\title{
Environmental Impacts of the Satellite Power System (SPS) on the Middle Atmosphere
}

October 1980

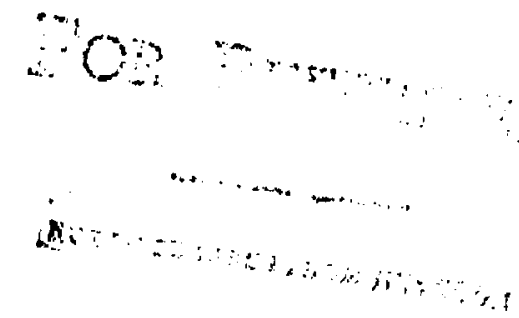

Prepared For:

U.S. Department of Energy

Office of Energy Research

Satellite Power System Project Division

Under Interagency Agreement Al -01-79ER-10035

DOE/NASA

Nivl :

Satellite Power System

Concept Development

and

Evaluation Program 
NOTICE

This report was prepared as an account of work sponsored by the United States Government. Neither the United States nor the United States Department of Energy, nor any of their employees, makes any warranty, express or implied, or assumes any legal liability or responsibility for the accuracy, completeness, or usefulness of any information, apparatus, product, or process disclosed, or represents that its use would not infringe privately owned rights. Reference herein to any specific commercial product, process, or service by trade name, mark, manufacturer, or otherwise, does not necessarily constitute or imply its endorsement, recommendation, or favoring by the United States Government or any agency thereof. The views and opinions of authors expressed herein do not necessarily state or reflect those of the United States Government or any agency thereof.

Ava1lable from:

National Technical Information Service (NTIS)

U.S. Department of Comnerce

5285 Port Royal Road

Springfield, Virginia 22161

Price:

$\begin{array}{ll}\text { Printed Copy: } & \$ 6.00 \\ \text { Microflche: } & \$ 4.00\end{array}$

For sale by the Superintendent of Documents, U.S. Govermment Printing Ofice, Washington, I).C. 20402 


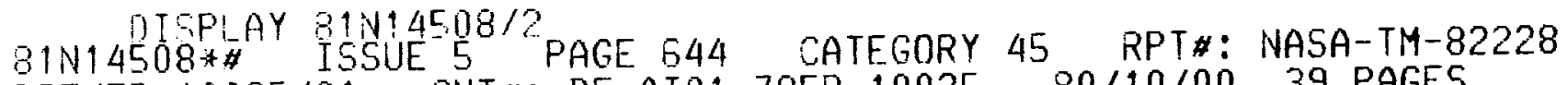
JDE /ER-10035/01 CNTH: DE-AI01-79ER-10035 80/10/00 39 PAGES UNCLASSIF IED DOCUMENT

UTTL: Environmental impacts of the satellite power system (SPS) on the middle atmosphere

CORP: National Aeronautics and Space Administration. Ames Research Center, Moffett Field, Calif. AUAIL.NTIS SAP: HC A03/MF AC1

MAJS: /*AIR POLLUTIÓN/*ATMOSPHERIC EFFECTS/*EARTH ATMOSPHERE/*ENVIRONMENT EFFECTS/*MATHEMATICAL MODELS/*SATELLITE SOLAF POWER STATIONS/*TECHNOLOGY ASSESSMENT

MINS: / ATMOSPHERIC MODELS/ CONTAMINANTS/ LAUNCH YEHICLES/ LOWER ATMOSPHEPE/ SAJELLITE SOLAR ENERGY CONVERSION/ TECHNOLOGICAL FORECASTING

ABF: futhor

ABS: The heavy lift launch vehicles (HLLV) proposed for use in constructing satellite power systems (SFS) would deposit various contaminants ir the middle atmosphere, contaminants that would conceivable have adverse effects on climate and upper air structure. These contaminants consist of the major constitutents of water vapor, hydrogen, carbon dioxide, and carbon monoxide, and the minor constituents of sulfur dioxide and nitric oxide in the rocket effluent, as well as nitric oxide formed during reentry. To assess the magnitudes of the effects, new models or modified ENTEF: existing models were constructed. 


$$
\text { - }-
$$


DOE/ER/110035-01

Dist. Category uc-34b

\section{Environmental Impacts of the Satellite Power System (SPS) on the Middle Atmosphere}

October 1980

Prepared For:

U.S. Department of Energy

Office of Energy Research

Satellite Power System Project Division

Washington, D.C. 20545

Prepared by:

NASA - Ames Research Center

Moffett Field, CA 94035

Under Interagency Agreement Al -01-79ER-10035

\section{DOE/NASA}

Satellite Power System

Concept Development

and

Evaluation Program 
. 


\section{ABSTRACT}

The heavy-1ift launch vehicles (HLLV) proposed for use in constructing satellite power systems (SPS) would deposit varfous contaminants in the middle atmosphere, contaminants that could concelvably have adverse effects on climate and upper air structure. These contaminants consist of the major constituents of water vapor, hydrogen, carbon dioxide, and carbon monoxide, and the minor constituents of sulfur dioxide and nitric oxide in the rocket effluent, as well as nitric oxide formed during reentry.

To assess the magnitudes of the effects, we have constructed new models or modified existing models. They are: one- and two-dimensional photochemical models, a plume model, a noctilucent cloud and contrail mode1, a reentry model, and a model of the lower Ionosphere, all of which are described in detail in the report. Using a scenario of 400 launches per year for 10 years, we have performed assessments and arrived at the following conclusions: (1) The buildup of water vapor, nitric oxide, $\mathrm{CO}_{2}$, and $\mathrm{CO}$, and sulfur dioxide, including a possible "corridor" effect (zonal enhancement centered on the launch latitude) is not likely to be significant. (2) Perturbations to odd-oxygen $\left(0,0_{3}\right)$ are not likely to be significant in that ozone total column density decreases are probably less than $0.1 \%$; in fact, ozone Increases due to No deposition may occur. (3) Perturbations to odd-hydrogen species $\left(\mathrm{H}, \mathrm{OH}, \mathrm{HO} \mathrm{O}_{2}\right)$ are not likely to be significant in the stratosphere and mesosphere; however, there could be a doubling of thermospheric hydrogen. (4) The effect of water vapor emission on global cloud coverage would be negligible. Although the possibility of impressive local noctilucent cloud displays near the launch latitude is posstble, we do not expect them to have any climatic significance. (5) Perturbations of HF, VLF, and ELF communication links will be minimal compared to normal varlability, however, D-region electron concentrations and conductivity may be greatly enhanced locally during atmospheric reentry. 
Portions of this work were contributed by the following organizations:

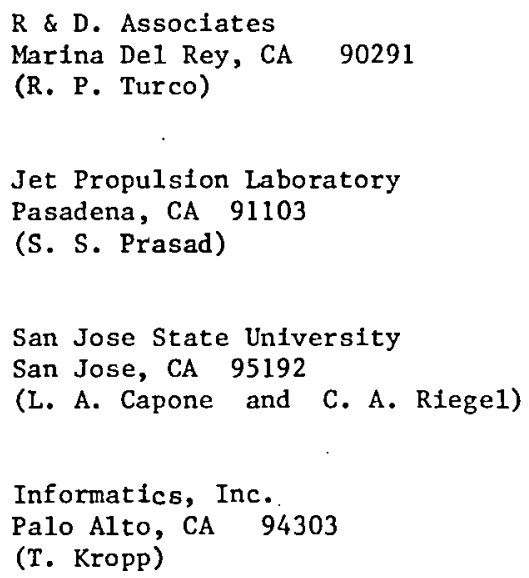

The authors wish to thank the following revlewers for many helpful comments and suggestions:

Dr. Paul Bernhardt, Stanford University, Stanford, CA 94305

Dr. Kenneth Brubaker, Argonne National Laboratory, Argonne, IL 60439

Dr. Ralph Cicerone, Scripps Institution of Oceanography, La Jolla, CA 92093

Dr. Billy McCormac, Lockheed Palo Alto Research Laboratory, Palo Alto, CA 94304

Dr. Richard Vondrak, SRI International, Menlo Park, CA 94025

Dr. John Zinn, Los Alamos Scientific Laboratory, Los Alamos, NM 87545

Dr. Edwin Danielson, Ames Research Center, NASA, Moffett Field, CA 94035

Dr. Tatsuo Shimazaki, Ames Research Center, NASA, Moffett Fleld, CA 94035

Dr. Brian Toon, Ames Research Center, NASA, Moffett Field, CA 94035 
TABLE OF CONTENTS

Page

ABSTRACT . . . . . . . . . . . . . . . . . . . . . . . . . . . . 1

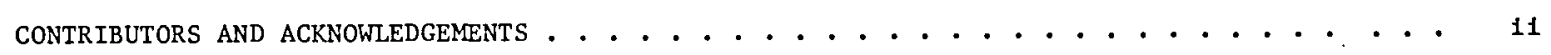

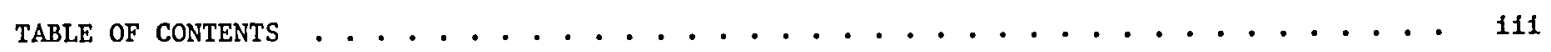

LIST OF FIGURES . . . . . . . . . . . . . . . . . . . . . . . . . . IV

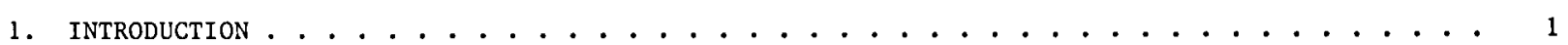

2. ATMOSPHERIC PHOTOCHEMICAL MODELS . . . . . . . . . . . . . . . . . . . . . . 1

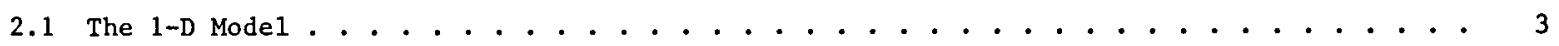

2.2 The 2-D Mode1 . . . . . . . . . . . . . . . . . . . . . . . 5

2.3 Simplified Plume Model . . . . . . . . . . . . . . . . . . . . . 8

3. A NOCTLlUCENT ClOUd MOdEL AND ROCKET CONTRAILS . . . . . . . . . . . . . . . . . . . . . 9

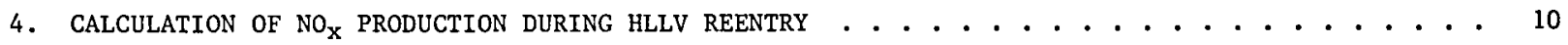

5. A MODEL OF THE LOWER IONOSPHERE . . . . . . . . . . . . . . . . . . . . . . . . 13

6. THE ACCUMULATION AND DISPERSion OF ROCKET EXHAUST CONTAMINANTS . . . . . . . . . . . . . 15

6.1 Water vapor . . . . . . . . . . . . . . . . . . . . . . 15

6.2 Nitric oxide . . . . . . . . . . . . . . . . . . . . . . . . . . . . . . . .

6.3 Carbon Dioxide and Carbon Monoxide ........................ 17

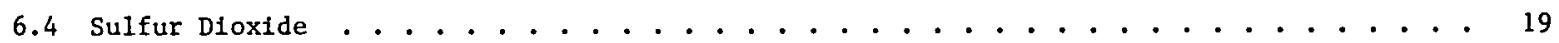

7. PERTURBATIONS TO ODD-OXYGEN AND ODD-HYDROGEN . . . . . . . . . . . . . . . . . . . . 19

8. ROCKET CONTRAILS AND NOCTILUCENT ClOUdS . . . . . . . . . . . . . . . . . . . . 21

9. PERTURBATIONS OF THE LOWER IONOSPHERE . . . . . . . . . . . . . . . . . . . . . . . . . 24

9.1 Long-Term Global Effects . . . . . . . . . . . . . . . . . . . . . . 24

9.2 Short-Term Local Effects . . . . . . . . . . . . . . . . . . . . . 25

9.3 Uncertainties . . . . . . . . . . . . . . . . . . . . . . . 25

10. POSSible Climatic EFFECTS Of LARge ROCKET OPERATIONS . . . . . . . . . . . . . . . . . 26

11. SUMMARY . . . . . . . . . . . . . . . . . . . . . . . . . . . . . 38

REFERENCES . . . . . . . . . . . . . . . . . . . . . . . . . . . 29 
Ffg. 1. Deposition rates of water vapor, molecular oxygen, and nitric oxide durfng HLLV launch . . 1

Fig. 2. Eddy diffusion coefficient profile......................... 3

Fig. 3. Vertical profiles of $\mathrm{H}, \mathrm{OH}, \mathrm{H}_{2} \mathrm{O}, \mathrm{O}\left({ }^{3} \mathrm{P}\right), \mathrm{O}_{3}$, and NO calculated with $1-\mathrm{D}$ mode1....... 5

FIg. 4. Vertical profiles of $\mathrm{H}, \mathrm{OH}, \mathrm{H}_{2} \mathrm{O}, \mathrm{O}\left({ }^{3} \mathrm{P}\right), \mathrm{O}_{3}$, and NO calculated with $2-\mathrm{D}$ mode1...... 4

Fig. 5. Schematic outline of the noctilucent cloud mode1 . . . . . . . . . . . . . 10

Fig. 6. Predicted ice crystal and meteoric dust size distributions in the noctilucent cloud model 10

Fig. 7. Possible entry trajectories . . . . . . . . . . . . . . . . . . . . . 1l

Fig. 8. Mercator plot of entry trajectories ......................... 12

F1g. 9. Vertical distributions of No $x$ produced by each HLLV reentry . . . . . . . . . . . 12

F1g. 10. Production of No as a function of altitude and latitude . . . . . . . . . . . . 12

F1g. 11. Computed absolute 1ncrease in water vapor concentration after 10 years of HLLV launches . 15

F1g. 12. Computed increase in mesospheric nitric oxide after 10 years of HLIV reentries . . . . 17

Fig. 13. Nitric oxide concentrations in a dispersing trail formed during the reentry of an HLLV . . 18

F1g. 14. Computed Increase in the mixing ratio of carbon dioxide after 10 years of HLLV launches . 18

Fig. 15. Predicted absolute changes in $\mathrm{H}, \mathrm{OH}$, and $\mathrm{HO}_{2}$ concentrations due to water vapor emissions by HLLVs................................ 19

Fig. 16. (a) Predicted relative increase in the total column ozone denstty as a function of latitude and season .......................... 21 (b) Predicted changes in ozone concentration as a function of altitude......... 21

Fig. 17. Predicted changes in ozone and $O\left({ }^{3} \mathrm{P}\right)$ due to water vapor emission of HLLVs . . . . . . 22

Ffg. 18. Simulated HLLV plume characteristics . . . . . . . . . . . . . . . . . 23

LIST OF TABLES

Table 1. HLLV Launch Effluents ...............................

Table 2. Families of Specles ...............................4

Table 3. Description of the Noctilucent Cloud Model . . . . . . . . . . . . . . . 9

Table 4. Ion Reaction Rate Coefficlents .......................... 13

Table 5. Simulated Unperturbed Daytime Globally Averaged Ionosphere . . . . . . . . . . . 15

Table 6. Predicted Ionospheric Perturbations Due to Nitric Oxide Deposition . . . . . . . 24

Table 7. Nitric Oxide and Electron Concentrations Near Reentry . . . . . . . . . . . . 25 


\section{INTRODUCTION}

The U.S. Department of Energy is responsible for examining new or alternative energy sources. One such potential energy source which has been proposed is that of solar power collected by suitable satellite systems and transmitted to Earth in the form of many microwave beams. Among the important factors, which must be addressed as part of the feasibility investigation for such a systen, is the environmental impact of the heavy-1ift launch vehicles (HLLV) necessary for the construction of solar power systems in space. The purpose of the study reported here is to assess the effects on the middle atmosphere (stratosphere, mesosphere, and lower lonosphere) of launchIng about 400 HLLV's per year for 10 years or more; other investigating teams are dealing with environmental effects on the troposphere, thermosphere, and upper Ionosphere.

The principal emfssions from the HLLV that can be expected to modify atmospheric composition are water vapor, hydrogen, and carbon dioxide deposited by rocket launch engines (Table 1), and nitric oxide formed during reentry. In addition, small amounts of nitric oxide and sulfur dioxide are expected to be formed in the combustion process and deposited during launch. Water vapor and hydrogen deposition profiles given in units of molecules $\mathrm{cm}^{-1}$ are presented in Fig. 1 ; note the discontinuity at an altitude of $56 \mathrm{~km}$, where the first stage, which uses methane as fuel, cuts off and the second stage, which uses hydrogen as fuel, ignites. Also note the large increase in the deposition rate as the vehicle approaches an altitude of $120 \mathrm{~km}$; the increase is a result of the nearly horizontal flight near the end of the trajectory and burnout at $120 \mathrm{~km}$. Carbon dioxide, a product of methane combustion, is also enitted up to first stage burnout; its deposition rate has been estimated to be 0.4 of the water vapor rate (Ref. 1). The emission rate of nitric oxide during the launch phase is also shown in Fig. 1 . The emission rate of sulfur dioxide is estimated by assuming that the first-stage fuel contains $0.05 \%$ sulfur. $^{1}$ Because the production of nitric oxide during reentry is the subject of a rather lengthy calculation, we defer its discussion to a later section.

Because of the complexity of the physical processes occuring in the stratosphere, mathematical models are required to obtain quantitative estimates of the effects of HLLV operations. General models that consider the interactions of radiation, chemistry, and dynamics are beyond current capabilities. Hence, a range of more specific models must be used to describe each area of concern.

Table 1. HLLV Launch Effluents (Ref. 1)

\begin{tabular}{lcc}
\hline Effluent & $\begin{array}{c}\text { Mass per launch, } \\
\text { tonnes }\end{array}$ & $\begin{array}{c}\text { Altitude Interval, } \\
\text { km }\end{array}$ \\
\hline $\mathrm{H}_{2} \mathrm{O}$ & 3860 & $10-125$ \\
$\mathrm{H}_{2}$ & 160 & $10-125$ \\
$\mathrm{CO}_{2}$ & 1650 & $10-56$ \\
$\mathrm{CO}$ & 750 & $10-56$ \\
$\mathrm{SO}_{2}$ & $<0.5$ & $10-56$ \\
\hline
\end{tabular}

In the following sections we discuss the atmospheric photochemical models used in this

assessment, Including a model for high-altitude cloud formation, a calculation of nitric oxide production during reentry, and an ionospheric model. We then apply the models to the assessment of HLLV effects on the middle atmosphere, evaluating both possible global effects as well as short-term local effects, and we discuss uncertainties in the assessment. Finally, we summarize our conclusions, 1dentifying those effects that could be significant and may require further study.

\section{ATMOSPHERIC PHOTOCHEMICAL MODELS}

The atmosphere 1s extremely difficult to model. Even the tenuous stratosphere and mesosphere present great difficulties. In fact, atmospheric simulation by mathematical models has been called the "last

\footnotetext{
${ }^{1}$. L. Brubaker, Argonne National Laboratory, private communication, 1980 .
} 
great unsolved problem of classical physics." Such statements usually refer to the simulation of atmospheric motions, but even the considerably less complex problem of simulating atmospheric photochemistry introduces a number of approximations that depart from reality. For example, the set of chemical species and reactions that can be accommodated is necessarily restricted in scope, atmospheric variability cannot be simulated, and large-scale long-period averaging must be invoked.

The transport of species is simplified to an even greater degree. One-dimensional models, which in some sense simulate average global conditions, can represent only vertical transport and usually do so with the so-called "eddy diffusivity." Two-dimensional models are less limited in that they can include an "eddy-diffusion tensor," which represents motions leading to mixing, and meridional bulk motions. In the model used in the study reported here, the bulk velocities are obtained by zonally averaging the wind fields predicted by three-dimensional models; eddy coefficients were obtained by an adjustment procedure based on matching computed tracer distributions with their observed distributions.

To carry out the required assessments most efficiently and realistically, two photochemical models are used: a one-dimensional (1-D) model and a two-dimensional (2-D) model. The 1-D model, which contains over 50 species, is most useful for investigating globally or hemispherically averaged changes in composition; it is also capable of simulating a much larger system of species and reactions than the 2-D model, which is limited to about 25 species below $55 \mathrm{~km}$ and 9 species above $55 \mathrm{~km}$. The 2-D model, on the other hand, can stmulate meridional variations in composition changes and is thus able to treat possible seasonal and "corridor" effects; the latter refers to enhanced changes in a zone containing the launch or reentry windows. Because both models have been described in detail in the literature (Refs. 2-5), only brfef descriptions are glven here. Both models are based on the continuity equations for trace constituents

$$
\frac{\partial n_{i}}{\partial t}+\underset{\nabla}{V} \cdot\left(n_{i} y+\Phi_{i}\right)=P_{i}-L_{i}
$$

where $P_{1}$ and $L_{1}$ are production and loss rates, respectively, for the 1 th constituent, $y$ is the meridional bulk velocity, $\Phi_{i}$ is the "eddy flux" representing large-scale eddy motions, and $n_{i}$ is the number density of the $i t h$ constituent. In the $1-D$ model the velocity $v i s$, of course, absent, and
the eddy flux is written as

$$
\Phi_{i}=-K_{e}\left[\frac{\partial n_{1}}{\partial t}+\left(\frac{1}{H}+\frac{d T}{T d z}\right) n_{f}\right] \hat{e}_{z},
$$

where $\hat{e}_{z}$ is a vertical unit vector, $K_{e}$ is the eddy diffusivity, and $T$ and $H$ are the temperature and mean atmospheric scale helght, respectively. Because the 1-D model extends into the lower thermosphere, molecular diffusion cannot be neglected; a term $\Phi_{1} \mathrm{D}$ representing molecular diffusive flux must therefore be added to $\Phi_{1}$ :

$$
\Phi_{i}^{D}=-D_{i}\left[\frac{\partial n_{1}}{\partial z}+\left(\frac{1}{H_{1}}+\frac{1}{T} \frac{d T}{d z}\right) n_{i}\right] \hat{e}_{z} .
$$

Here, $H_{i}$ is the scale height of the 1 th constituent

$$
H_{i}=\frac{k T}{m_{1} g}=\frac{\bar{m}}{m_{1}} H \text {; }
$$

$m_{1}$ and $i n$ are the molecular mass of the $i$ th constituent and mean molecular mass, respectively, $k$ is the Boltzmann constant, and $g$ is the gravitational acceleration. The 2-D mode1, which does not extend into the thermosphere, ignores molecular diffusion. However, the eddy diffusion is more complicated than in the 1-D model because it is a tensor, that is, it contains "off-dfagonal" elements,

$$
\Phi_{1}=-K_{\tilde{e}} \cdot\left[\nabla_{1}+\left(\frac{1}{H}+\frac{1}{T} \frac{d T}{d z}\right) \hat{e}_{z} n_{1}\right] \text {, }
$$

which are important below $25 \mathrm{~km}$. 


\subsection{The 1-D Mode1}

The 1-D model extends from an altitude of $10 \mathrm{~km}$ to $120 \mathrm{~km}$ with a 2-km grid spacing; time steps are variable, depending on the nearness to equilibrium. The form of the flux equation used in the model is slightly different from that given above in that mixing fractions rather than number densities are used. The flux equation, which now contains both eddy and molecular diffusion terms, is

$$
\Phi_{i}=-\left[\frac{\left(K_{e}+D\right)}{\gamma} \frac{\partial \rho_{i}}{\partial z}+\frac{D}{H \gamma}\left(\frac{m_{i}}{\bar{m}}-1\right) \rho_{i}\right] \hat{e}_{z},
$$

where $\rho_{1}$ is the mixing fraction,

$$
\gamma=\frac{T(z)}{T_{0} M_{0}} \exp \left[\int_{z_{0}}^{z} \frac{d z^{\prime}}{H\left(z^{\prime}\right)}\right]
$$

and $\mathrm{T}_{O}$ and $\mathrm{M}_{\mathrm{O}}$ are atmospheric temperature and number density, respectively, at a reference altitude, $z_{0}$. The vertical profile of eddy diffusion used in the model is shown in Fig. 2.

Solutions of the species continuity equations, which are based on approximate, but very stable and efficient, numerical integration schemes, often violate mass conservation within groups of related species such as the nitrogen oxides (NO, $\mathrm{NO}_{2}, \mathrm{NO}_{3}, \mathrm{~N}_{2} \mathrm{O}_{5}, \mathrm{HNO}_{3}$ ). This problem is overcome in the model by employing a technique that accurately monitors the total concentrations of nearly conserved sets, or families, of compounds (Ref. 2); the concept of aeronomic families is well-known in aeronomy. Our technique uses an equivalent continuity equation for an entire family of gases, which is obtained by summing the continuity equations of all the family members after each is multiplied by an appropriate factor, $\alpha_{i}$, representing the number of odd-atoms of the type considered in the species. The criterion for assigning $\alpha$ is based on the time constant for switching oddatoms among species; if the time constant is short $\alpha \geq 1$; but if it is long, $\alpha=0$. Thus, summing (1) for a particular set of species we obtain:

$\frac{\partial S_{\ell}}{\partial t}=P_{S \ell}-L_{S \ell}-\frac{\partial \phi_{\ell}}{\partial z} ; \quad \ell=1,2, \ldots L$,

where $\ell$ is the family index,

$$
\begin{aligned}
\mathrm{s}_{\ell} & =\sum_{\{i\}_{\ell}} \alpha_{i} \rho_{i}, \\
\mathrm{P}_{S \ell}-\mathrm{L}_{\mathrm{S} \ell} & =\sum_{\{i\}_{\ell}} \alpha_{i}\left(\gamma \mathrm{P}_{i}-\rho_{i} \mathrm{~L}_{i}\right), \\
\phi_{\ell} & =\sum_{\{i\}_{\ell}} \alpha_{i} \phi_{i},
\end{aligned}
$$

and $\{i\}_{\ell}$ indicates the subset of species in the lth family.

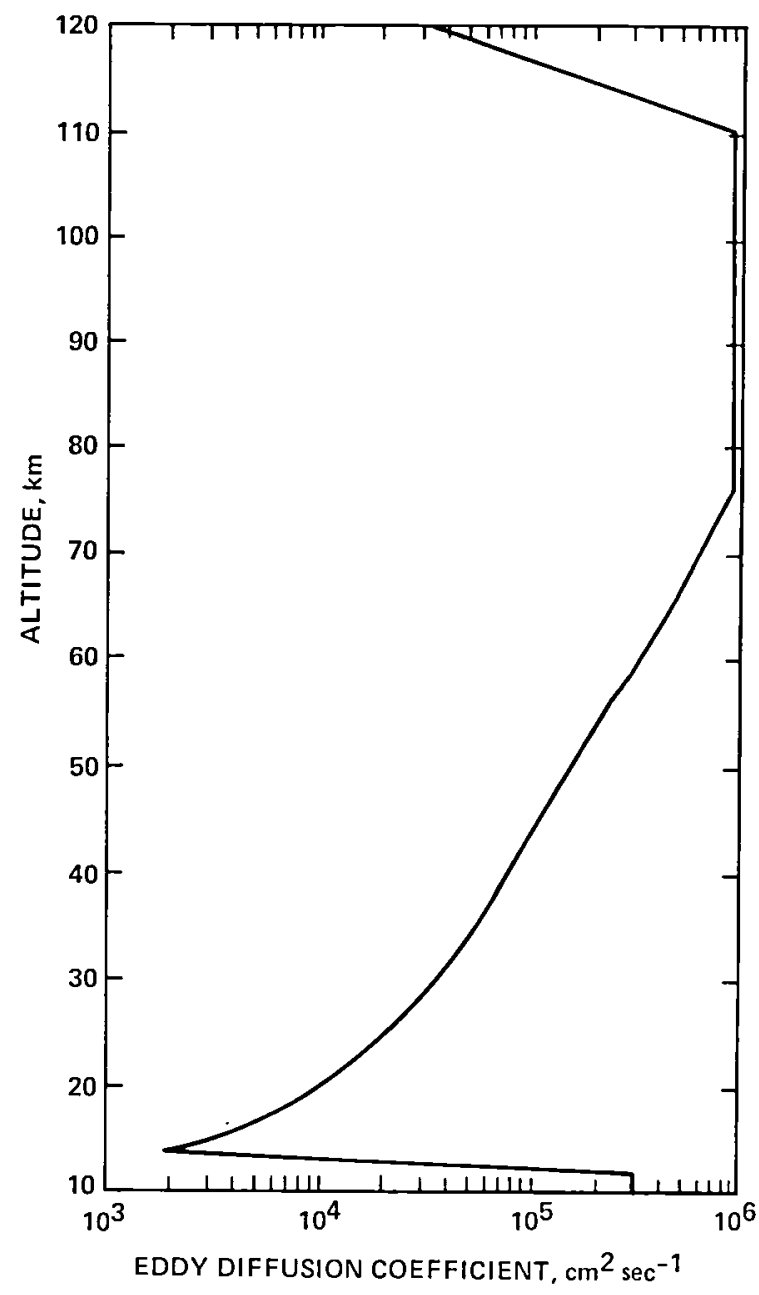

Fig. 2. The eddy diffusion coefficient (K) profile used in our one-dimensional model studies. 
The family flux, which follows from (6), is

$$
\phi_{\ell}=-\frac{(\mathrm{K}+\mathrm{D})}{\gamma} \frac{\partial \mathrm{S}_{\ell}}{\partial \mathrm{z}}-\frac{\mathrm{DS}_{\ell}}{\mathrm{H} \gamma}\left(\frac{\mathrm{m}_{\ell}}{\overline{\mathrm{m}}}-1\right)
$$

The factor $\mathrm{m}_{\ell} / \overline{\mathrm{m}}$ in (12) is a weighted average value,

$$
\frac{m_{\ell}}{\bar{m}}=\sum_{\{i\}_{\ell}} \alpha_{i} \rho_{i}\left(\frac{m_{i}}{\bar{m}}\right) / \sum_{\{i\}_{\ell}} \alpha_{i} \rho_{i},
$$

which is nearly time invariant, because the ratios of species concentrations within a family are nearly constant under most conditions. Obviously, the species boundary conditions, which we discuss later, are also additive for families.

What makes the family technique useful is that the net photochemistry for the family, represented by $\mathrm{P}_{S}-\mathrm{L}_{\mathrm{S}}$ in (8), usually contains only slow processes that affect the total family abundance, and precludes the rapid cyclic chemical interactions that occur between family members. Accordingly, the sumed continuity equations in (8) are inherently more stable than the individual species continuity equations, and their solution can be made very accurate.

Family concentrations obtained from (8) are used to correct the species abundances computed using (1) and (6). The families of species utilized in our model are given in Table 2 in the hierarchical order

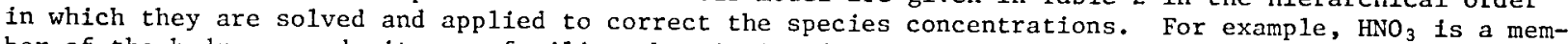
ber of the hydrogen and nitrogen families, but it is adjusted during the hydrogen correction cycle and remains fixed during the nitrogen cycle.

\begin{tabular}{|c|c|}
\hline Hydn & $(1), a \mathrm{OH}(1), \mathrm{HO}_{2}(1), \mathrm{H}_{2} \mathrm{O}_{2}(2), \mathrm{HNO}_{2}(1), \mathrm{HNO}_{3}(1), \mathrm{HOCl}(1)^{b}$ \\
\hline Carb & $\mathrm{CH}(1), \mathrm{CH}_{2}(1), \mathrm{CH}_{3}(1), \mathrm{CHO}(1), \mathrm{CH}_{2} \mathrm{O}(1), \mathrm{CH}_{3} \mathrm{O}(1), \mathrm{CH}_{3} \mathrm{O}_{2}(1), \mathrm{CH}_{4} \mathrm{O}_{2}(1)$ \\
\hline & $\mathrm{N}(1)$, NO(1), $\mathrm{NO}_{2}(1), \mathrm{NO}_{3}(1), \mathrm{HNO}_{2}(1), \mathrm{HNO}_{3}(1), \mathrm{N}_{2} \mathrm{O}_{5}(2), \mathrm{ClONO}_{2}(1) b, \mathrm{BrONO}_{2}(1)^{b}$ \\
\hline & $(1), \mathrm{SO}(1), \mathrm{SO}_{2}(1), \mathrm{SO}_{3}(1), \mathrm{HSO}_{3}(1), \mathrm{H}_{2} \mathrm{SO}_{4}(1)$ \\
\hline & $\mathrm{Cl}(1), \mathrm{ClO}(1), \mathrm{ClO}_{2}(1), \mathrm{ClONO}_{2}(1), \mathrm{HOCl}(1)$ \\
\hline hlorine: & $\mathrm{Cl}(1), \mathrm{ClO}(1), \mathrm{ClO}_{2}(1), \mathrm{ClONO}_{2}(1), \mathrm{HCl}(1), \mathrm{HOCl}(1)$ \\
\hline & $\mathrm{Br}(1), \mathrm{BrO}(1), \mathrm{HBr}(1), \mathrm{BrONO}_{2}(1)$ \\
\hline & $\begin{array}{l}\mathrm{O}(1), \mathrm{O}_{3}(1), \mathrm{O}^{1} \mathrm{D}(1), \mathrm{NO}_{2}(1), \mathrm{NO}_{3}(2), \mathrm{HNO}_{3}(1), \mathrm{N}_{2} \mathrm{O}_{5}(3), \mathrm{C} 10(1), \mathrm{ClO}_{2}(2), \mathrm{ClON} \\
\mathrm{BrO}(1), \mathrm{BrONO}_{2}(2)\end{array}$ \\
\hline
\end{tabular}

Table 2.- Families of Species

The number in parentheses is the species weight $\alpha$ within the family.

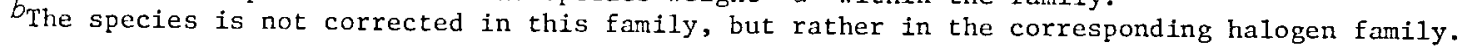

Two types of families are easily recognizable: one in which the family members recombine in pairs (hydrogen, nitrogen, oxygen), the other in which the members recombine with species outside of the family, or do not recombine at all (the other families). Families can also be classified according to their internal chemistry: the members of some families cycle rapidly among themselves in reaction loops (hydrogen, nitrogen, oxygen, chlorine), while the members of other families react in a chain, one species leading to the next, from the family source to its sink (carbon, sulfur). Note that the consideration of families requires the identification of the atom carriers in key aeronomic processes. For example, in the oxygen family we can readily find reactions that might not seem to involve oxygen atom transfer or recombination, but actually do; thus, the reaction of $\mathrm{ClO}$ with No to form $\mathrm{C} 1$ and $\mathrm{NO}_{2}$ (which is rapidly photolyzed to NO and 0 ) does not involve any odd-oxygen production or loss according to our criteria for odd-oxygen (see Table 2). Thus, the family concept is helpful in understanding aeronomic reaction mechanisms.

The chemical rate coefficients used in the model are essentially those tabulated in Ref. 6, except that the photolysis rate for No is taken from Refs. 7 and 8 . Furthermore, we include a source of mesospheric $N\left({ }^{2} D\right)$ (first excited state of $N$ ) due to the ionization of No by solar Lyman-a radiation:

$$
\mathrm{NO}+\mathrm{h \nu} \mathrm{L}_{\alpha} \rightarrow \mathrm{NO}^{+}+\mathrm{e}
$$




$$
\mathrm{NO}^{+}+\mathrm{e} \rightarrow \mathrm{N}\left({ }^{2} \mathrm{D}\right)+\mathrm{O}
$$

(14) concluded

In the model, diurnal averaging of photodissociation rates and reaction rate coefficients is performed using, respectively, the techniques reported in Refs, 9 and 10.

For each species we specify a lower boundary flux $\phi_{i 0}$ and an upper boundary flux, $\phi_{j u}$, which may be fixed or have a specified time dependence. At the lower boundary we also include a flux component,

$$
\phi_{B_{i}}=v_{B_{i}}\left(n_{B_{i}}-n_{i_{1}}\right) \text {, }
$$

by defining the "velocity" at the boundary, $v_{B_{i}}$, and concentration, $n_{B_{i}}$ (if $n_{B_{i}}=0$, our code sets $\phi_{\mathrm{B}_{i}}=0$ automatically); $\mathrm{n}_{i_{1}}$ is computed by the model. Whenever we use boundary condition (15), we usually set the boundary velocity, $v_{B_{i}}$, equai to $1 \mathrm{~cm} \mathrm{sec}{ }^{-1}$, which is estimated from typical tropospheric mixing rates. A justification for this approach together with its mathematical application is given in Ref. 3. Upper boundary conditions are imposed in a somewhat similar manner except that allowance must be made for the escape of hydrogen. The mean escape flux of $\mathrm{H}$ atoms is about $10^{8} \mathrm{~cm}^{-2} \mathrm{sec}^{-1}\left(\operatorname{Ref}^{2} 11\right)$, which must be included in the computations of both $\mathrm{H}$ and $\mathrm{H}_{2}$. We specify the upper boundary fluxes as

$$
\left.\begin{array}{rl}
\phi_{\mathrm{H}} & =b \mathrm{n}_{\mathrm{H}}-2 a \mathrm{n}_{\mathrm{H}_{2}}, \\
\phi_{\mathrm{H}_{2}} & =a n_{\mathrm{H}_{2}}
\end{array}\right\}
$$

with the total escape flux $\phi_{\mathrm{T}}$ given by

$$
\phi_{\mathrm{T}}=\phi_{\mathrm{H}}+2 \phi_{\mathrm{H}_{2}}=\mathrm{bn}_{\mathrm{H}} \text {. }
$$

The constant $b$ is then determined from simu1taneous estimates of the escape flux and $n_{H}$, while a must be estimated from the flux of $\mathrm{H}_{2}$ at $120 \mathrm{~km}$.

In Fig. 3, 1-D model predictions for the ambient atmosphere are compared with observations. The agreement between prediction of atomic oxygen, $O\left({ }^{3} \mathrm{P}\right)$, and its observation is reasonable considering the large zenith angle of the observation; the high-altitude computed concentrations are perhaps a factor of 2 too large between 90 and $100 \mathrm{~km}$, but at other altitudes the agreement is quite good. Computed ozone concentrations are generally within the error bar of the KruegerMinzner (Ref. 16) empirical model, although the high-altitude (above $45 \mathrm{~km}$ ) predicted concentrations are somewhat too small. Predictions for $\mathrm{OH}$ and water vapor appear to lie within the range of observed values; however, it should be remarked that the range of observed water vapor is quite broad, extending from as low as 2 ppbv to 10 ppbv. Also, the $\mathrm{OH}$ observations were made at large solar zenith angles whereas the computed values are for average mid-latitude daytime conditions; to correspond to the same conditions, the predicted values would have to be reduced by a factor of $\sim 2$. The predicted nitric oxide abundance in the stratosphere lies well within the range of measurements. However, in the upper mesosphere and lower thermosphere, there is disagreement; this difference may be due in part to the large zenith angle of the observations and in part to adjustments needed in the mesospheric No photochemical sink and in the diffusion rate.

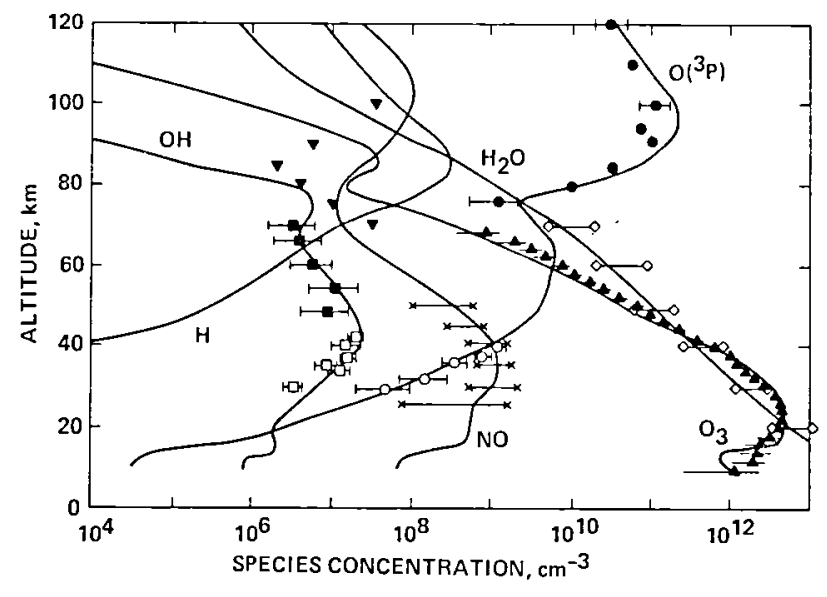

Fig. 3. Vertical profiles of $\mathrm{H}, \mathrm{OH}, \mathrm{H}_{2} \mathrm{O}, \mathrm{O}\left({ }^{3} \mathrm{P}\right), \mathrm{O}_{3}$, and No calculated with the one-dimensional model.

The concentrations are average daytime values. Measured concentrations shown are:

$\mathrm{OH}$ : $\quad--1$ Anderson (Ref. 12); White Sands, N. Mex., in April with solar zenith angle of $86^{\circ}$

Hrl Anderson (Ref. 13); Palestine, Tex., in July and January with solar zenith angle of $80^{\circ}$

$\mathrm{H}_{2} \mathrm{O}:-\odot$ Summary and review of measurements given

$O\left({ }^{3} \mathrm{P}\right): 1 \bullet-1$ Howlett et al. (Ref. 15); White Sands, N. Mex., in December with solar zenith angle close to $90^{\circ}$

to-l Summary and review of measurements given in Ref. 6

$0_{3}: \quad 1-1$ Krueger and Minzner (Ref. 16)

NO: $\quad x \rightarrow$ Summary and review given in Hudson and Reed (Ref. 6)

- Baker et al. (Ref. 17); White Sands, N. Mex., in October with solar zenith angle of $92^{\circ}$ 


\subsection{The 2-D Mode1}

The 2-D model extends from the surface to an altitude of $90 \mathrm{~km}$ in $2.5-\mathrm{km}$ steps and from 1 at. $80^{\circ} \mathrm{N}$ to lat. $80^{\circ} \mathrm{S}$ in $5^{\circ}$ steps; time steps are fixed at 1 day. The form of the flux equation used in the model is that given in (5) above. The temperature $\mathrm{T}$, which is a function of season and latitude as well as altitude, is taken from Ref. 18 for altitudes below $20 \mathrm{~km}$ and from Ref. 19 for higher altitudes. The two-dimensional divergence operator is represented in the meridional plane of a sphere by

$$
\underline{\nabla} \cdot \equiv\left(\frac{\hat{\mathrm{e}}_{\theta}}{R \cos \theta} \frac{\partial}{\partial \theta} \cos \theta+\hat{\mathrm{e}}_{z} \frac{\partial}{\partial z}\right) \text {, }
$$

where $\theta$ is the latitude, $\hat{e}_{\theta}$ is the tangential unit vector, and $R$ is the radius of Earth.

Transport parameters are specified in the model for each season. They are of two types: bulk velocity, which represents large-scale mean meridional motion, and "eddy diffusivity," which represents smaller scale motions. The parameters that we have adopted are physically reasonable and lead to satisfactory predictions of observed tracer distributions.

The mean meridional circulation is obtained by the kinematic method from the averaged equation of mass continuity, which states that

$$
\frac{\partial \rho}{\partial t}+\underline{\nabla} \cdot(\rho \underset{\sim}{ })=0
$$

where $\rho$ is the atmospheric bulk density and $\underline{y}$ is the large-scale atmospheric velocity. With the assumption that the density field is in a steady state, the approximate form of this equation in spherical coordinates is

$$
\frac{1}{R \cos \theta} \frac{\partial}{\partial \theta}(\bar{\rho} \bar{v} \cos \theta)+\frac{\partial(\bar{\rho} \bar{w})}{\partial z}=0
$$

where the overbar denotes an average with respect to time and longitude, and $\bar{v}$ and $\bar{w}$ are the mean meridional and vertical velocity components. Equation (20) implies the existence of a "stream function" $\psi$ for the total flux such that

$$
2 \pi R \bar{\rho} \bar{v} \cos \theta=-\frac{\partial \psi}{\partial z} ; \quad 2 \pi R \bar{\rho} \bar{w} \cos \theta=\frac{1}{R} \frac{\partial \psi}{\partial \theta}
$$

If the distributions of $\bar{\rho}$ and $\bar{v}$ are known, the first of equation (21) can be integrated vertically to obtain $\psi$, and $\overline{\mathrm{w}}$ can then be obtained from the second.

The density was obtained from the hydrostatic equation using temperatures discussed previously. The mean meridional circulation is based on that published by Cunnold et al. (Ref. 20), which was extrapolated upward to $90 \mathrm{~km}$. The resulting stream function satisfies (21).

The eddy fluxes are modeled by diffusion coefficients $\mathrm{K}_{\mathrm{yy}}$, $\mathrm{K}_{\mathrm{yz}}$, and $\mathrm{K}_{\mathrm{zz}}$ (the local " $\mathrm{y}$ " axis is tangent to the meridian; i.e., $\mathrm{dy}=\mathrm{Rd}$ ). The magnitude of $\mathrm{K}_{\mathrm{zz}}$ in this model is generally somewhat smaller than that in a one-dimensional model because vertical transport in two-dimensional models is affected by large-scale bulk motion $(w)$ as well as by eddy mixing. The assumed values of $\mathrm{K}_{\mathrm{yy}}$, which is the horizontal analog of $\mathrm{K}_{\mathrm{zz}}$, are strongly latitude-dependent, but height-independent.

The most interesting of the $\mathrm{K}_{i j}$, however, is the "off-diagonal" $\mathrm{K}_{\mathrm{yz}}\left(\equiv \mathrm{K}_{\mathrm{zy}}\right)$ because it leads to an apparent counter-gradient flux of ozone. It has been convincingly argued by Newall (Ref. 27) that the "mixing surfaces" in the lower stratosphere slope more steeply toward the pole than do the surfaces of potential temperature. That is, parcels of ozone moving poleward in the lower stratosphere tend also to move farther downward in the transport region to altitudes where their destruction becomes less efficient. Hence we see a buildup of ozone column density at high latitudes. Such an effect is associated with diabatic processes, which cause the relative slopes of surfaces of constant mixing and constant potential temperature to shift. One can in principle calculate the $\mathrm{K}_{\mathbf{i j}}$ by computing the variances of observed winds over a long period of time. In practice, one can obtain only order-of-magnitude estimates in this way. Our $K_{i j}$, which are based on observed tracer distributions, are consistent with the orderof-magnitude estimates obtained from wind-variance calculations. In order to facilitate computation of the $K_{i j}$, we employ a suggestion by Brasseur (Ref. 22) that they be expressed in the form 


$$
K_{i j}=\theta_{1 j}(\theta) z_{i j}(z)
$$

where $\theta$ is a function of latitude alone and $z$ is a function of height alone (note that our $z_{y y}=1$ ). These functions are readily adjusted to yield $\mathrm{K}$-fields that result in smooth distributions of trace constituents.

End boundaries are taken at 1 at. $80^{\circ} \mathrm{S}$ and 1 at. $80^{\circ} \mathrm{N}$ because meridional fluxes are expected to be sma11 at those latitudes. Hence, the end boundary conditions are taken to be zero flux of all constituents across the vertical boundaries. The upper boundary conditions are glven by setting the fluxes equal to zero for all species except $\mathrm{H}$, NO, and $O\left({ }^{3} \mathrm{P}\right)$. We have checked the upper boundary conditions (at $90 \mathrm{~km}$ ) for the various species against results from a one-dimensional model that extended up to $120 \mathrm{~km}$. It was found that the effect of choosing a mixing equilibrium condition at the upper boundary had very little effect on any of the constituents at altitudes below $50 \mathrm{~km}$. The lower boundary condition used for all species except $\mathrm{N}_{2} \mathrm{O}, \mathrm{CH}_{4}, \mathrm{HNO}_{3}, \mathrm{NO}_{2}, \mathrm{O}_{3}, \mathrm{HCl}, \mathrm{H}_{2} \mathrm{O}_{2}$, and the halocarbons, is chemical equilibrium because of their short lifetimes against chemical loss. Because $\mathrm{HNO}_{3}, \mathrm{HCl}$, and $\mathrm{H}_{2} \mathrm{O}_{2}$ are water soluble, their number densities are set equal to zero at the lower boundary. The number densities of $\mathrm{CH}_{4}, \mathrm{NO}_{2}$, and $\mathrm{N}_{2} \mathrm{O}$ are fixed at $3.7 \times 10^{13} \mathrm{~cm}^{-3}, 3 \times 10^{9} \mathrm{~cm}^{-3}$, and $7.5 \times 10^{12} \mathrm{~cm}^{-3}$, respectively, at the lower boundary, and that of $0_{3}$ is fixed at $6 \times 10^{11} \mathrm{~cm}^{-3}$ in order to conform to measured values.

We now turn our attention to the numerical solution of the governing equations. The method of "time splitting" is used to facilitate the computation; that is, the chemistry and transport portions of the equations are in general solved at different time steps. The technique for the "chemistry" step is discussed first; the technique that applies to transport is described in Ref. 5 .

For altitudes of $55 \mathrm{~km}$ and below the chemical rate equations are solved using the following type of implicit technique. Equation (1) leads to the finite difference form

$$
\frac{n_{i}^{j+1}-n_{i}^{j}}{\tau}=P_{i}^{j+1}-L_{1}^{j+1} \equiv Q_{i}^{j+1},
$$

In which the superscript $j$ indicates the index of the time step $\tau$. Equation (23) can be linearized by taking the first term in a Taylor series expansion about $Q_{i} j$ :

$$
\frac{n_{i}^{j+1}-n_{i}^{j}}{\Delta t}=Q_{i}^{j}+\sum_{k=1}^{m} \frac{\partial Q_{i}^{j}}{\partial n_{k}}\left(n_{k}^{j+1}-n_{k}^{j}\right) .
$$

The $m$ members of the set of mass conservation equations are thus coupled and require solution by inversion of a large matrix at each grid point. Diurnal averaging of photodissociation rates and reaction rate coefficlents is performed in a manner similar to that of the 1-D model.

At altitudes above $55 \mathrm{~km}$, the kinetic equations become sufficiently stiff that the foregoing technique fails. In order to solve the equations for high altitudes, we simplify the system by eliminating all constituents except $\mathrm{O}\left({ }^{3} \mathrm{P}\right), \mathrm{O}_{3}, \mathrm{O}\left({ }^{1} \mathrm{D}\right), \mathrm{OH}, \mathrm{HO}_{2}, \mathrm{H}, \mathrm{H}_{2} \mathrm{O}$, and $\mathrm{NO}$. To solve the kinetic equations, we assume $O\left({ }^{3} \mathrm{P}\right), O\left({ }^{1} \mathrm{D}\right)$, and $\mathrm{O}_{3}$ to be in photochemical equilibrium with each other, and also assume that $\mathrm{OH}$, $\mathrm{HO}_{2}$, and $\mathrm{H}$ are in photochemical equilibrium with each other. We then compute total odd hydrogen $\left(\mathrm{HO}_{\mathrm{x}}=\mathrm{OH}+\mathrm{HO}_{2}+\mathrm{H}\right.$ in this case $)$ and odd oxygen $\left(\mathrm{O}_{\mathrm{x}}=O\left({ }^{3} \mathrm{P}\right)+\mathrm{O}_{3}+O\left({ }^{1} \mathrm{D}\right)\right)$ concentrations by solving the coupled equations for $\mathrm{O}_{\mathrm{x}}$ and $\mathrm{HO}_{\mathrm{x}}$. The computed concentrations are then partitioned among member species by assuming photochemical equilibrium abundance ratios.

To assess the influence of ozone on the temperature structure (and thus the chemical composition) of the upper stratosphere and lower mesosphere, we have included a heating and cooling code. The heating algorithm is developed from the work of Lacis and Hansen (Ref. 23). Their method, a parametric treatment based on accurate multiple-scattering computations, includes the effects of Earth's albedo. (Earth's albedo is assumed to be constant and equal to 0.34 ; see Ref. 24, p. 2-2). The vertical distributions of ozone both above and below the calculation point are accounted for in the calculation of the absorbed and scattered solar radiation. Because the heating rate is dependent on the zenith angle and the number of hours of daylight, diurnally averaged heating rates are calculated as described in Ref. 9 . The heating rates are calculated at each latitude and altitude every 7 days so that the changing solar position and number of hours of daylight are taken into account. 
The cooling rates are computed from a Newtonian cooling model (Ref. 25) such that

$$
R(\theta, P)=A(\theta, P)+\sum_{i} B(P) \Delta T(\theta, P),
$$

where $R$ is the cooling rate (in degrees/day), $\Delta T$ is the model-calculated temperature minus the standard atmosphere reference temperature, and $A(\theta, P)$ and $B(P)$ are latitude- and pressure-dependent constants. The $A(\theta, P)$ were determined by requiring the radiative cooling to exactly balance the radiative heating for the standard reference temperature $(\Delta T=0)$ and ozone profiles. The $B(P)$ were taken from Ref. 25.

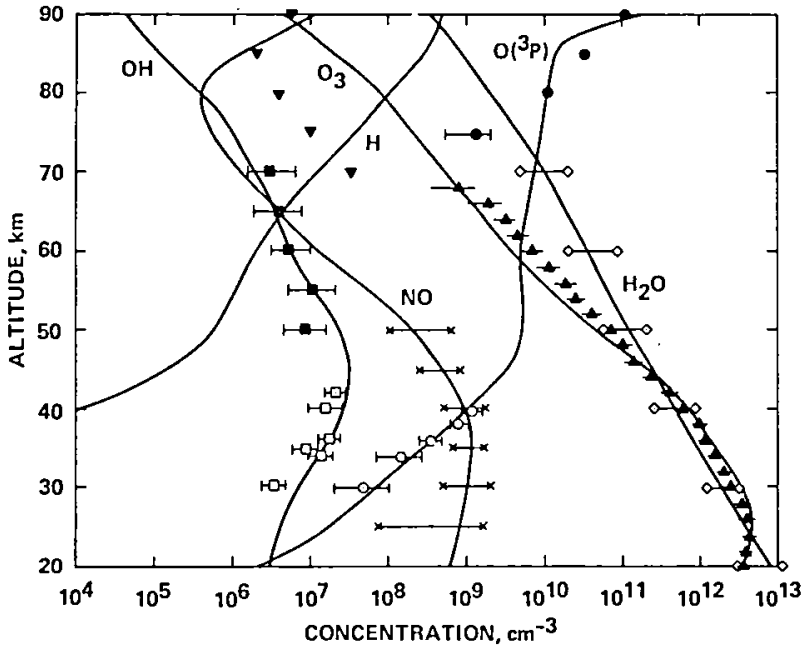

Fig. 4. Vertical profiles of $\mathrm{H}, \mathrm{OH}, \mathrm{H}_{2} \mathrm{O}, \mathrm{O}\left({ }^{3} \mathrm{P}\right), \mathrm{O}_{3}$, and No concentrations calculated with the twodimensional model. The measured concentrations are as shown in Fig. 3.

In Fig. 4, 2-D model predictions for the ambient atmosphere (autumn, lat. $40^{\circ} \mathrm{N}$ ) are shown. The agreement with observational data is about the same as that obtained with the 1-D model, except for No; the mesospheric concentrations appear to be about an order of magnitude too small between 55 and $85 \mathrm{~km}$. We attribute the low predicted values to the absence of a mesospheric source of NO and to slow upward transport of No from the stratosphere; the vertical eddy diffusivity in the mesosphere is probably a factor of 3 too 1 ow, a state of affairs that is not readily correctable, because of limitations in calculational stability.

\subsection{Simplified P1ume Mode1}

To complement our one-dimensional (1-D) and twodimensional analysis of the widespread photochemical effects caused by rocket emissions, we utilize a simple model of an expanding rocket plume to study potentially important local effects of the rocket plume. The model is applied for both rocket launch and reentry events, and is predicated on several approxima-

tions. The simulated launch-reentry plume is oriented vertically and has cylindrical symmetry. The 1-D model is used to sample the entire plume, although the plume may be truncated in altitude extent to simulate a slanted flight trajectory. The plume is given an initial width corresponding to a short period of expansion. The rocket injectants at each height are averaged over the initial area of the trail, and these concentrations, when added to the ambient concentrations, represent the starting conditions for the 1-D mode1.

The area of the rocket trail is assumed to increase with time according to the relation (Ref.48),

$$
A=2 K\left(t+t_{0}\right) \text {, }
$$

where $A$ is the area $\left(\mathrm{cm}^{2}\right), K$ is the effective horizontal diffusion coefficient ( $\left.\mathrm{cm}^{2} / \mathrm{sec}\right)$ and $t$ ime $t=0$ at the initial expansion time of the plume $(\mathrm{sec}), t_{0}$. Obviously the initial area and time can be related by $A_{O}=2 \mathrm{Kt}_{0}$. The constituents under study are always taken to be uniformly distributed across the plume.

For a chemically active species in an expanding plume, it is easy to show that the rate of change of its average plume concentration, $n$, due to expansion only is,

$$
\left.\frac{d n}{d t}\right|_{\text {expansion }}=-\left(n-n_{a}\right) \frac{1}{A} \frac{d A}{d t}
$$

where $\mathrm{n}_{\mathrm{a}}$ is the ambient concentration. Equation (27) presumes that chemistry occurs uniformly across the plume, that the plume expands by mixing in air containing an ambient abundance of each gas, and that mixing within the plume is instantaneous. If $\mathrm{K}$ is constant, equation (27), by virtue of equation (26), becomes, 


$$
\left.\frac{\mathrm{dn}}{\mathrm{d} t}\right|_{\text {expansion }}=-\frac{\mathrm{n}-\mathrm{n}_{\mathrm{a}}}{\mathrm{t}+\mathrm{t}_{\mathrm{o}}}
$$

This term is readily incorporated in a $1-D$ model as a pseudochemical process.

The expanding cylindrical plume model just described is functionally similar to a Fickian diffusion plume mode1. In the latter case, one may consider the rate at which molecules diffuse out of an imaginary cylinder centered in a growing Gaussian plume. At times exceeding the initial spreading time, $t_{0}$, the two plume treatments give essentially the same solution.

\title{
3. A NOCTILUCENT CLOUd MODEL AND ROCKET CONTRAILS
}

With the deposition of large quantities of water vapor in the mesosphere by SPS rockets, it is likely that exhaust contrails will form. An important question is whether these contrails can evolve into, or trlgger, widespread and persistent high-altitude clouds or enhance naturally occurring clouds. At high latitudes in the summer, the meteorological conditions at the mesopause are such that tenuous nightluminous (noctilucent) clouds (NLC) are a not infrequent sight. However, at low latitudes, NLC are never seen, except occasionally following rocket launches.

Obviously, it would be most informative to test for the occurrence of rocket clouds from a liquid-fueled rocket with an appropriately designed atmospheric experiment. It is also useful, however, to make detailed physical simulations of rocket contrails and clouds. We have constructed a comprehensive noctilucent cloud model as part of this assessment. A summary description of the model is given in Table 3 , and a schematic outline of the interactions between the four basic elements of the model, water vapor, Ice crystals, meteoric dust and air ions, is given in FIg. 5. Details of the physics and photochemistry used in the model are given in Ref. 28 and in references therein. Reference 15 also summarizes existing noctflucent cloud observations and reviews previous NLC modeling work. By performing a variety of sensitivity studies with the model, Ref. 28 concludes that the model yields a reasonable simulation of typical noctilucent cloud properties. Here, the model is used to estimate the effects of rocket water vapor emissions on local and global cloudiness.

Table 3. Description of the Noctilucent Cloud Model

\begin{abstract}
Basic structure One-dimensional model, $70-105 \mathrm{~km}$ in $0.5-\mathrm{km}$ steps, thirty-five particle size bins from $0.001 \mu \mathrm{m}$ to $2.56 \mu \mathrm{m}$ radius. Particle volume doubles between size bins. Temperature, density, and diffusion coeffictent profiles are fixed. Solar fluxes are calculated at each height in 96 wavelength bins. Time-dependent or steady-state simulations.
\end{abstract}

Basic elements

Water vapor Fixed concentration at the lower boundary, source from methane decompositfon, loss by photolysis. Water condenses on and evaporates from ice crystals.

Ice crystals Formed by nucleation of meteoric dust, ion nucleation, and homogeneous nucleation, all involving water vapor. Microphysics includes growth, coagulation (with other ice crystals and dust), sedimentation, diffusion, and charging. Crystal shape effects (cubic, hexagonal, and amorphous $i c e$ ) are also included.

Meteoric dust Produced from ablating meteors as $10-\AA$ smoke. Microphysics includes nucleation into ice crystals, coagulation, release from evaporating crystals, sedimentation, diffusion, and charging.

Ionization Formed by galactic cosmic ray bombardment and No photoionization. Lost by ion-electron and ion-ion recombination, nucleation, and collection by particles. Electrons are produced by photoemission.

Figure 6 shows the predicted size distributions for ice and dust particles in an ambient noctilucent cloud. Also shown is the change in the ice particle size spectrum at $82 \mathrm{~km}$ resulting from a doubling of the ambient water vapor. The optical depth of the ambient (model) cloud at $550 \mathrm{~nm}$ is about $7 \times 10^{-5}$, in line with values estimated from NLC observations. The optical depth of the perturbed cloud is $1.3 \times 10^{-4}$. Thus, the opacity is roughiy doubled when water vapor is doubled. 


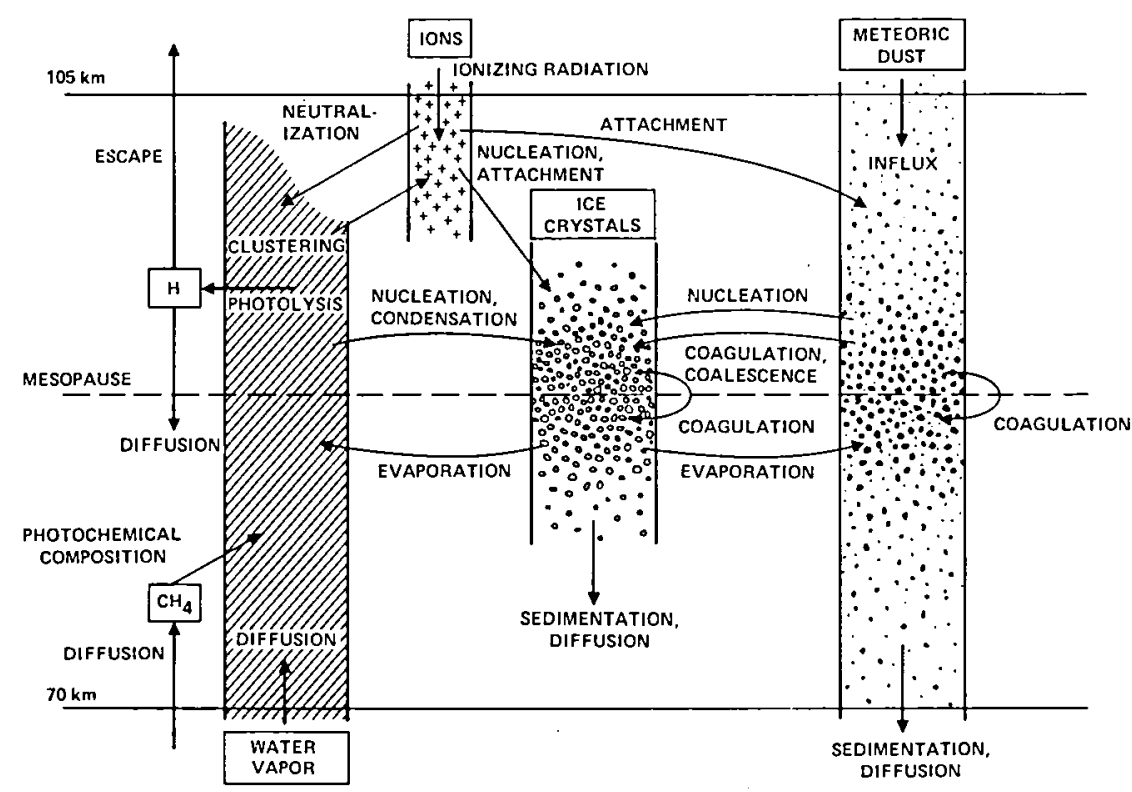

Fig. 5. Schematic outline of the noctilucent cloud model showing the major elements of the model (water vapor, fce crystals, meteoric dust and air ions), and their basic interactions.

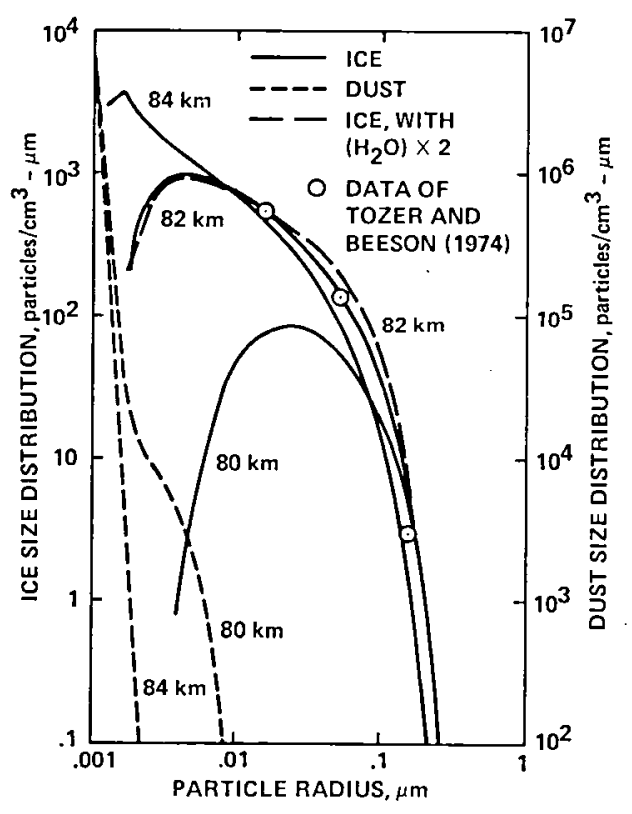

Fig. 6. Predicted ice crystal and meteoric dust size distributions in the noctilucent cloud model. Size distributions are given at several altitudes in the cloud region. The size distribution ' $A$ ' of Tozer and Beeson (Ref. 27) is compared to the model prediction (thelr optical measurements did not yield a unique size profile). The crosshatched area indicates the change in the ice particle size distribution caused by a doubling of the water vapor concentration.

\section{CALCULATION OF NO $_{x}$ PRODUCTION DURING HLLV REENTRY}

According to Ref. 29, the average mass of the HLLV at reentry is 452.6 metric tonnes. The total projected area of the craft is determined from the figures given in Ref. 29 as approximately $2,280 \mathrm{~m}^{2}$. The initial orbit height of the craft is given as $450 \mathrm{~km}$. Reference 29 specifies also that the deceleration of the HLLV during reentry sha11 be less than $1.4 \mathrm{~g}$. The report does not specify, however, the entry flight trajectory or the lift and drag characteristics of the gliding body needed in a trajectory calculation. Presumably such aerodynamic data have not yet been generated. In order to estimate the amounts and spatial distributions of $\mathrm{NO}_{x}$ produced during the reentry flight, therefore, the following assumptlons have been made:

1. The functional relationship between the drag coefficient and the angle of attack of the craft is the same as for the Space Shuttle Orbiter, as given by Ref. 30 .

2. The lift coefficients of the vehicle are expressible as a product of the lift coefficient values of the Space Shuttle Orbiter given by Ref. 30 and an arbitrary fixed constant not greater than unity. Controlling lift coefficients in this manner would be possible, for instance, by varying the angle of wing flap.

3. The angle of attack remains fixed at a high value inftially. When the craft reaches a 
certain Intermediate altitude (of about 70 to $80 \mathrm{~km}$ ), the angle of attack is changed at a steady rate to a low value.

4. The orbit of the HLLV is inclined $45^{\circ}$ to the equator.

5. The end point of the entry flight defined as the point where altitude is $50 \mathrm{~km}$ ) is 1 at. $40^{\circ} \mathrm{N}$ and long. $120^{\circ} \mathrm{W}$, so that the craft could land on an alrfleld in central California.

6. Atmosphere rotates with the Earth without any slip.

The entry trajectory can be varied by varying (1) the duration of the retro-rocket burn at the orbit (the amount of fuel required for this purpose would be very small, and so its mass is ignored, (2) the lift coefficient (i.e., flap angle), (3) the initial angle of attack, (4) the final angle of attack, (5) the altitude at which the angle of attack begins to decrease, and (6) the rate at which the angle of attack is changed. In the present work, these variable parameters were changed over a wide range in order to generate a family of possible entry trajectorles that satisfies the condition of maximum allowed deceleration of $1.4 \mathrm{~g}$. The calculation requires a stralght forward numerical integration of the Newtonian equations of motion in two dimensions. Earth was assumed to be a perfect sphere, and the atmospheric data of the U.S. Standard Atmosphere (Ref. 31) were used for the calculation. Figure 7 shows the profiles of such flight trajectories. As indicated, the trajectories are produced by varying retro- $\Delta \mathrm{V}$, that is, the velocity decrement achieved by firing the retro-rockets, between -0.105 and $-0.110 \mathrm{~km} / \mathrm{s}^{-1}$. At the altitude of $120 \mathrm{~km}$, these two $\Delta \mathrm{V}$ values produce entry velocities of 7.588 and $7.583 \mathrm{~km} / \mathrm{s}^{-1}$, and entry angles of $-0.896^{\circ}$ and $-1.103^{\circ}$, respectively, of these, three typical trajectorles were selected for computation of the NO $x$ production rate. According to the distance required for the reentry flight to end, they are referred to here as "shallow," "nominal," and "steep" trajectories, as shown. The Mercator projection of the entry trajectories is shown in Fig. 8.

The rate of $\mathrm{NO}_{\mathrm{x}}$ production along these trajectories was calculated by the method of Park (Ref. 32). In brief, the method assumes that the amounts of $\mathrm{NO}_{x}$ produced by a spacecraft are the same as that produced by a circular cone having the same overall chord length, overall surface area, and angle of attack. Such a method is shown in Ref. 32 to yield approximately the same amount of $\mathrm{NO}_{x}$ as a real spacecraft with a blunt nose, at least up to the point where such an "exact" calculation was possible. The computer code used by Park (Ref. 32) was run in the present study. The code calculates the thermodynamic variables simultaneously with the chemical rate equations to compute the concentrations of $N$ and No in the flow around a given cone. The computation is carried out until the flow leaves the trailing edge of the spacecraft. Then the assumption is made that the No molecules are chemically frozen, but that all $\mathrm{N}$ atoms convert to No in the wake. This assumption slightly overestimates the total No concentration in the wake because it ignores the mutual destruction process $\mathrm{N}+\mathrm{NO} \rightarrow \mathrm{N}_{2}+0$. But such error would be small because (1) the total concentration of $\mathrm{N}$ is quite small, and (2) there are far more $O_{2}$ than No molecules in the wake for $N$ atoms to react with.

The calculation yields the number of $\mathrm{NO}_{\mathrm{x}}$ molecules deposited along the wake per unit length of the wake for each entry flight. By integrating the number of the molecules along the trajectory, one obtains the integrated (regionally or globally) number of $\mathrm{NO}_{x}$ molecules produced. The overall efficlency of $\mathrm{NO}_{\mathbf{x}}$ formation is calculated from the relation

$$
\begin{aligned}
n & =\frac{\text { total chemical energy of } \mathrm{NO}_{\mathrm{x}} \text { produced }}{\text { inftial kinetic energy of HLLV }} \\
& =\frac{\text { total number of } \mathrm{NO}_{\mathrm{x}} \text { molecules produced } \times \varepsilon}{(1 / 2) \mathrm{M} \mathrm{V}_{\mathrm{i}}{ }^{2}}
\end{aligned}
$$




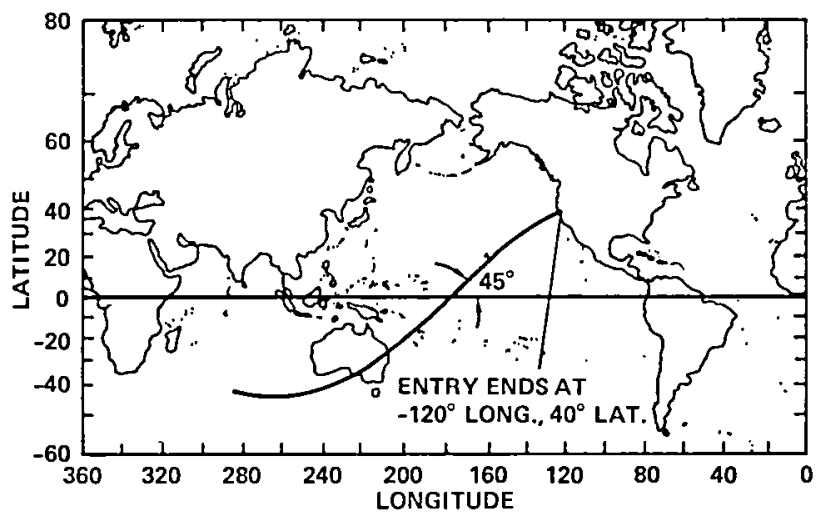

Fig. 8. Mercator plot of the entry trajectories considered.

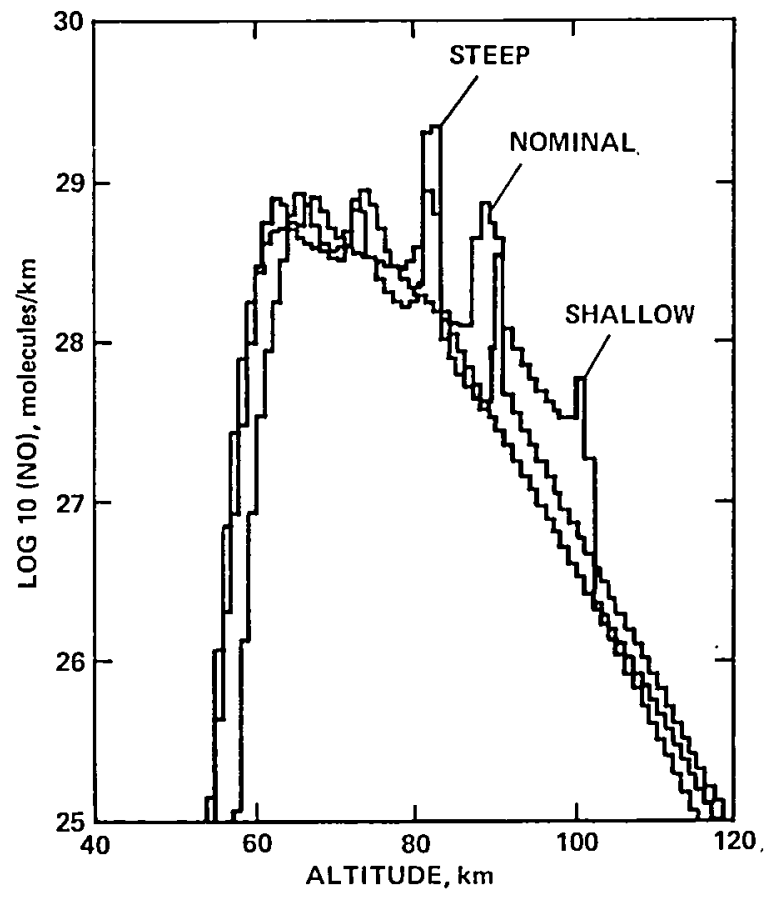

Fig. 9. Vertical distributions of $\mathrm{NO}_{x}$ produced by each HLLV reentry. where $\varepsilon$ is the formation energy of one No molecule, $\varepsilon=1.515 \times 10^{-12} \mathrm{erg},(0.95 \mathrm{eV}), \mathrm{M}$ is the mass of HLLV, and $v_{i}$ is the entry velocity. To be consistent with the twodimensional atmospheric model adopted in the present work, the global atmosphere was partitioned by the latitude increment of $5^{\circ}$ and altitude increment of $2.5 \mathrm{~km}$. Figure 9 shows the distribution of $\mathrm{NO}_{\mathrm{x}}$ by altitude. The total amounts of $\mathrm{NO}_{\mathrm{x}}$ produced per flight, in terms of mass equivalent of NO, and the efficiency of conversion of the initial kinetic energy into No are:

\begin{tabular}{lcc} 
Trajectory & Mass of $\mathrm{No}_{\mathrm{x}}$, tonnes & Efficiency, $n$ \\
\hline Shallow & 53.0 & 0.0124 \\
Nominal & 65.5 & 0.0153 \\
Steep & 71.2 & 0.0167
\end{tabular}

The efficiency values obtained here are nearly equal to those for the Space Shuttle Orbiter (Ref. 32) and for large meteoroids (Ref. 33).

Figure 10 shows the production of No molecules $\mathrm{cm}^{-3}$ as a function of altitude and latitude for the nominal entry case ( $45^{\circ}$ angle of attack).

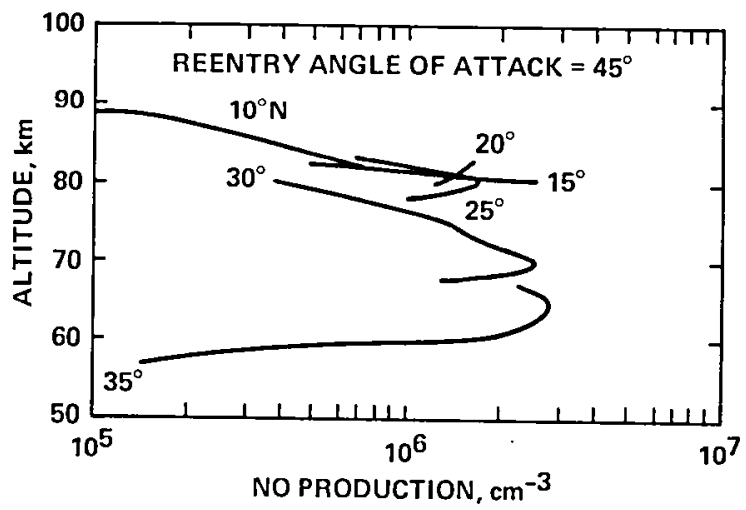

Fig. 10. Production of No as a function of altitude and latitude for the nominal entry case $\left(45^{\circ}\right.$ angle of attack). 


\section{A MODEL OF THE LOWER IONOSPHERE}

To assess the effect of compositional changes (i.e., in $\mathrm{H}_{2} \mathrm{O}$ and $\mathrm{NO}$ ) due to HLLV's on the structure of the lower lonosphere, it is necessary to construct a model that includes the appropriate 1on chemistry. The model used.here considers a total of 24 charged specles ( $1 . \mathrm{e}, \mathrm{O}^{+}, \mathrm{O}_{2}^{+}, \mathrm{NO}^{+}, \mathrm{N}_{2}^{+}, \mathrm{O}_{2}^{+} \cdot \mathrm{H}_{2} \mathrm{O}, \mathrm{H}_{3} \mathrm{O}^{+} \cdot \mathrm{OH}$, $\mathrm{H}^{+} \cdot \mathrm{H}_{2} \mathrm{O}, \mathrm{H}^{+} \cdot\left(\mathrm{H}_{2} \mathrm{O}\right)_{2}, \mathrm{H}^{+} \cdot\left(\mathrm{H}_{2} \mathrm{O}\right)_{3}, \mathrm{H}^{+} \cdot\left(\mathrm{H}_{2} \mathrm{O}\right)_{4}, \mathrm{NO}^{+} \cdot \mathrm{O}_{2}, \mathrm{NO}^{+} \cdot \mathrm{N}_{2}, \mathrm{NO}^{+} \cdot \mathrm{H}_{2} \mathrm{O}, \mathrm{NO}^{+} \cdot\left(\mathrm{H}_{2} \mathrm{O}\right)_{2}, \mathrm{NO}^{+} \cdot\left(\mathrm{H}_{2} \mathrm{O}\right)_{3}, \mathrm{O}^{-}, \mathrm{O}_{2}^{-}, \mathrm{O}_{3}^{-}, \mathrm{O}_{4}^{-}$, $\mathrm{CO}_{3}^{-}, \mathrm{CO}_{4}^{-}, \mathrm{NO}_{2}^{-}, \mathrm{NO}_{3}^{-}, \mathrm{NO}_{3}^{-} \cdot \mathrm{H}_{2} \mathrm{O}$, and electrons) in a given specified background neutral atmosphere consisting of $\mathrm{N}_{2}, \mathrm{O}, \mathrm{O}_{2}, \mathrm{O}_{3}, \mathrm{O}_{2}\left({ }^{1} \mathrm{~A}_{\mathrm{g}}\right)$, NO, $\mathrm{NO}_{2}$, and $\mathrm{H}_{2} \mathrm{O}$. The concentrations of minor specles were taken from the 1-D photochemical mode1 (see Sec. 2.1), except that the No concentrations between 70 and $80 \mathrm{~km}$ were set equal to $10^{7} \mathrm{~cm}^{-3}$ as recommended by Mitra (Ref. 34) and based on avallable theoretical results and observed ionospheric data. The basic principles used in constructing lower fonospheric models were described in several standard texts and monographs (e.g., Refs. 34-37).

Solar Lyman- $\alpha$ and $x$-rays and galactic cosmic rays constitute the sources of primary $\mathrm{N}_{2}^{+}, \mathrm{O}_{2}^{+}, \mathrm{O}^{+}$, and $\mathrm{NO}^{+}$ lons and electrons. The primary ions initiate the ion-molecule reactions 1 isted in Table 4; eventually, the positive ions are neutralized by electrons and negative lons. Negative Ions are formed by electron attachment to neutral species (mainly $\mathrm{O}_{2}$ and $\mathrm{O}_{3}$ ). Attachment infitates a number of negative ion reaction sequences (also listed in Table 4); again neutralization is the ultimate sink for negative charge. Clustering of positive ions to neutral species such as $\mathrm{N}_{2}, \mathrm{O}_{2}, \mathrm{CO}_{2}$, and to $\mathrm{H}_{2} \mathrm{O}$ In particular, is an extremely important process in the D-region because $1 \mathrm{t}$ is responsible for the conversion of the primary ions $0_{2}^{+}$ and $\mathrm{NO}^{+}$Into hydronium fons $\mathrm{H}^{+} \cdot\left(\mathrm{H}_{2} \mathrm{O}\right)_{\mathrm{n}}$. Accordingly, all known important clustering processes were included in the model. The high air density of the D-region insures that ion-molecule reactions will occur rapidly. In addition, the recombination of positive and negative charge occurs in the time scale of $-1 \mathrm{hr}$. Consequently, the charged species were assumed to be in a local steady-state condition, and their equilibrium number densities were obtained by solving the set of coupled chemical kinetic equations

$$
\mathrm{P}_{1}-\mathrm{L}_{1}=0 \text {, }
$$

where $P_{1}$ and $L_{1}$ are the production and loss rates of the 1 th 1 ion. The equations are coupled because the production of the ith lon generally involves many other ions, as is evident from Table 4 . Similarly, the loss of the $i$ th ion involves not only reaction with neutrals but also charge recombination processes.

Table 4. Ion Reaction Rate Coefficients Rate Coefficient $=\mathrm{AT}^{\beta} \exp (-\alpha / \mathrm{T})^{\alpha}$

\begin{tabular}{|c|c|c|c|}
\hline Reaction & $A^{b}$ & $\alpha$ & $B$ \\
\hline $\begin{array}{l}\mathrm{O}^{+}+\mathrm{N}_{2} \rightarrow \mathrm{NO}^{+}+\mathrm{N} \\
\mathrm{O}_{+}^{+}+\mathrm{O}_{2} \rightarrow \mathrm{O}_{2}^{+}+\mathrm{O} \\
\mathrm{N}_{2}^{+}+\mathrm{O}^{+} \rightarrow \mathrm{NO}_{+}^{+}+\mathrm{N} \\
\mathrm{N}_{+}^{+}+\mathrm{O}_{2} \rightarrow \mathrm{O}_{2}^{+}+\mathrm{N}_{2} \\
\mathrm{~N}_{2}^{+}+\mathrm{O}_{2} \rightarrow \mathrm{NO}^{+}+\mathrm{NO}\end{array}$ & $\begin{array}{l}3.6(-10) \\
3.4(-10) \\
1.4(-10) \\
6.4(-7) \\
1.0(-17)\end{array}$ & $\begin{array}{l}0 \\
0 \\
0 \\
0 \\
0\end{array}$ & $\begin{array}{l}-1.0 \\
-0.48 \\
0 \\
-1.67 \\
0\end{array}$ \\
\hline $\begin{array}{l}\mathrm{O}_{2}^{+}+\mathrm{NO} \rightarrow \mathrm{NO}^{+}+\mathrm{O}_{2} \\
\mathrm{O}_{2}^{+}+\mathrm{O}_{2}+\mathrm{M} \rightarrow \mathrm{O}_{4}^{+}+\mathrm{M} \\
\mathrm{O}_{4}^{+}+\mathrm{O}_{2}^{+} \mathrm{O}_{2}^{+}+\mathrm{O}_{3} \\
\mathrm{O}_{4}^{+}+\mathrm{H}_{2} \mathrm{O} \rightarrow \mathrm{O}_{2}^{+} \cdot \mathrm{H}_{2} \mathrm{O}+\mathrm{O}_{2} \\
\mathrm{O}_{2}^{+} \cdot \mathrm{H}_{2} \mathrm{O}+\mathrm{H}_{2} \mathrm{O} \rightarrow \mathrm{H}_{3} \mathrm{O}^{+} \cdot \mathrm{OH}+\mathrm{O}_{2}\end{array}$ & $\begin{array}{l}6.3(-10) \\
2.0(-30) \\
3.0(-10) \\
2.0(-9) \\
9.0(-10)\end{array}$ & $\begin{array}{l}0 \\
0 \\
0 \\
0 \\
0\end{array}$ & $\begin{array}{l}0 \\
0 \\
0 \\
0 \\
0\end{array}$ \\
\hline $\begin{array}{l}\mathrm{O}_{2}^{+} \cdot \mathrm{H}_{2} \mathrm{O}+\mathrm{H}_{2} \mathrm{O} \rightarrow \mathrm{H}^{+} \cdot \mathrm{H}_{2} \mathrm{O}+\text { products } \\
\mathrm{H}_{3} \mathrm{O}^{+} \cdot \mathrm{OH}+\mathrm{H}_{2} \mathrm{O} \rightarrow \mathrm{H}^{+} \cdot\left(\mathrm{H}_{2} \mathrm{O}\right)_{2}+\mathrm{OH} \\
\mathrm{H}^{+} \cdot \mathrm{H}_{2} \mathrm{O}+\mathrm{H}_{2} \mathrm{O}+\mathrm{M}+\mathrm{H}^{+} \cdot\left(\mathrm{H}_{2} \mathrm{O}\right)_{2}+\mathrm{M} \\
\mathrm{H}^{+} \cdot\left(\mathrm{H}_{2} \mathrm{O}\right)_{2}+\mathrm{M} \rightarrow \mathrm{H}^{+} \cdot\left(\mathrm{H}_{2} \mathrm{O}\right)+\mathrm{H}_{2} \mathrm{O}+\mathrm{M} \\
\mathrm{H}^{+} \cdot\left(\mathrm{H}_{2} \mathrm{O}\right)_{2}+\mathrm{H}_{2} \mathrm{O}+\mathrm{M} \rightarrow \mathrm{H}^{+} \cdot\left(\mathrm{H}_{2} \mathrm{O}\right)_{3}+\mathrm{M}\end{array}$ & $\begin{array}{l}3.0(-10) \\
3.0(-9) \\
2.75(-17) \\
9.6(11) \\
1.86(-17)\end{array}$ & $\begin{array}{l}0 \\
0 \\
0 \\
17100 \\
0\end{array}$ & $\begin{array}{l}0 \\
0 \\
-4 \\
-5 \\
-4\end{array}$ \\
\hline $\begin{array}{l}\mathrm{H}^{+} \cdot\left(\mathrm{H}_{2} \mathrm{O}\right)_{3}+\mathrm{M} \rightarrow \mathrm{H}^{+} \cdot\left(\mathrm{H}_{2} \mathrm{O}\right)_{2}+\mathrm{H}_{2} \mathrm{O}+\mathrm{M} \\
\mathrm{H}^{+} \cdot\left(\mathrm{H}_{2} \mathrm{O}\right)_{3}+\mathrm{H}_{2} \mathrm{O}+\mathrm{M} \rightarrow \mathrm{H}^{+} \cdot\left(\mathrm{H}_{2} \mathrm{O}\right)_{4}+\mathrm{M} \\
\mathrm{H}^{+} \cdot\left(\mathrm{H}_{2} \mathrm{O}\right)_{4}+\mathrm{M} \rightarrow \mathrm{H}^{+} \cdot\left(\mathrm{H}_{2} \mathrm{O}\right)_{3}+\mathrm{H}_{2} \mathrm{O}+\mathrm{M} \\
\mathrm{NO}^{+}+\mathrm{H}_{2} \mathrm{O}+\mathrm{M} \rightarrow \mathrm{NO}^{+} \cdot \mathrm{H}_{2} \mathrm{O}+\mathrm{M} \\
\mathrm{NO}^{+} \cdot \mathrm{H}_{2} \mathrm{O}+\mathrm{H}_{2} \mathrm{O}+\mathrm{M} \rightarrow \mathrm{NO}^{+} \cdot\left(\mathrm{H}_{2} \mathrm{O}\right)+\mathrm{M}\end{array}$ & $\begin{array}{l}1.95(11) \\
1.94(-17) \\
1.36(11) \\
7.9(-17) \\
4.4(-16)\end{array}$ & $\begin{array}{c}11000 \\
0 \\
8360 \\
0 \\
0\end{array}$ & $\begin{array}{l}-5 \\
-4 \\
-5 \\
-4.7 \\
-4.7\end{array}$ \\
\hline $\begin{array}{l}\mathrm{NO}^{+} \cdot\left(\mathrm{H}_{2} \mathrm{O}\right)_{2}+\mathrm{M} \rightarrow \mathrm{NO}^{+} \cdot \mathrm{H}_{2} \mathrm{O}+\mathrm{H}_{2} \mathrm{O}+\mathrm{M} \\
\mathrm{NO}^{+} \cdot\left(\mathrm{H}_{2} \mathrm{O}\right)_{2}+\mathrm{H}_{2} \mathrm{O}+\mathrm{M} \rightarrow \mathrm{NO}^{+} \cdot\left(\mathrm{H}_{2} \mathrm{O}\right)_{3}+\mathrm{M} \\
\mathrm{NO}^{+} \cdot\left(\mathrm{H}_{2} \mathrm{O}\right)_{3}+\mathrm{M} \rightarrow \mathrm{NO}^{+}:\left(\mathrm{H}_{2} \mathrm{O}\right)_{2}+\mathrm{H}_{2} \mathrm{O}+\mathrm{M}\end{array}$ & $\begin{array}{l}1.0(-14) \\
4.4(-16) \\
1.9(-12)\end{array}$ & $\begin{array}{l}0 \\
0 \\
0\end{array}$ & $\begin{array}{c}0 \\
-4.7 \\
0\end{array}$ \\
\hline
\end{tabular}


Table 4. Concluded

\begin{tabular}{|c|c|c|c|}
\hline Reaction & $A^{b}$ & $\alpha$ & $\beta$ \\
\hline $\begin{array}{l}\mathrm{NO}^{+} \cdot\left(\mathrm{H}_{2} \mathrm{O}\right)_{3}+\mathrm{H}_{2} \mathrm{O} \rightarrow \mathrm{H}^{+} \cdot\left(\mathrm{H}_{2} \mathrm{O}\right)_{3}+\mathrm{HNO}_{2} \\
\mathrm{NO}^{+}+\mathrm{CO}_{2}+\mathrm{M} \rightarrow \mathrm{NO}^{+} \cdot \mathrm{CO}_{2}+\mathrm{M}\end{array}$ & $\begin{array}{l}7.0(-11) \\
1.89(-22)\end{array}$ & $\begin{array}{l}0 \\
0\end{array}$ & $\begin{array}{r}0 \\
-3\end{array}$ \\
\hline $\begin{array}{l}\mathrm{NO}^{+} \cdot \mathrm{CO}_{2}+\mathrm{M} \rightarrow \mathrm{NO}^{+}+\mathrm{CO}_{2}+\mathrm{M} \\
\mathrm{NO}^{+} \cdot \mathrm{CO}_{2}+\mathrm{H}_{2} \mathrm{O} \rightarrow \mathrm{NO}^{+} \cdot \mathrm{H}_{2} \mathrm{O}+\mathrm{CO}_{2} \\
\mathrm{NO}^{+}+\mathrm{N}_{2}+\mathrm{M} \rightarrow \mathrm{NO}^{+} \cdot \mathrm{N}_{2}+\mathrm{M} \\
\mathrm{NO}^{+} \cdot \mathrm{N}_{2}+\mathrm{M} \rightarrow \mathrm{NO}^{+}+\mathrm{N}_{2}+\mathrm{M} \\
\mathrm{NO}^{+} \cdot \mathrm{N}_{2}+\mathrm{CO}_{2} \rightarrow \mathrm{NO}^{+} \cdot \mathrm{CO}_{2}+\mathrm{N}_{2}\end{array}$ & $\begin{array}{ll}3.1 & (4) \\
1.0 & (-9) \\
2.0 & (-31) \\
1.5 & (6) \\
1.0 & (-9)\end{array}$ & $\begin{array}{l}4590 \\
0 \\
0 \\
2450 \\
0\end{array}$ & $\begin{array}{l}-4 \\
0 \\
-4.4 \\
-5.4 \\
0\end{array}$ \\
\hline $\begin{array}{l}\mathrm{NO}^{+} \cdot \mathrm{N}_{2}+\mathrm{H}_{2} \mathrm{O} \rightarrow \mathrm{NO}^{+} \cdot \mathrm{H}_{2} \mathrm{O}+\mathrm{N}_{2} \\
\mathrm{O}_{3}+\mathrm{e} \rightarrow \mathrm{O}^{-}+\mathrm{O}_{2} \\
\mathrm{O}^{-}+\mathrm{O}_{3} \rightarrow \mathrm{O}_{3}^{-}+0 \\
\mathrm{O}^{-}+\mathrm{O}_{2}+\mathrm{O}_{2} \rightarrow \mathrm{O}_{3}^{-}+\mathrm{O}_{2} \\
\mathrm{O}_{2}+\mathrm{e}+\mathrm{N}_{2} \rightarrow \mathrm{O}_{2}^{-}+\mathrm{N}_{2}\end{array}$ & $\begin{array}{ll}1.0(-9) \\
1.0(-12) \\
7.0(-10) \\
1.0(-30) \\
1.0(-31)\end{array}$ & $\begin{array}{l}0 \\
0 \\
0 \\
0 \\
0\end{array}$ & $\begin{array}{l}0 \\
0 \\
0 \\
0 \\
0\end{array}$ \\
\hline 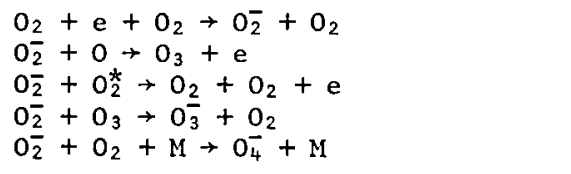 & $\begin{array}{l}1.8(-30) \\
3.3(-10) \\
2.0(-10) \\
3.0(-10) \\
1.0(-30)\end{array}$ & $\begin{array}{l}0 \\
0 \\
0 \\
0 \\
0\end{array}$ & $\begin{array}{l}0 \\
0 \\
0 \\
0 \\
0\end{array}$ \\
\hline $\begin{array}{l}\mathrm{O}_{2}^{-}+\mathrm{CO}_{2}+\mathrm{O}_{2} \rightarrow \mathrm{CO}_{4}^{-}+\mathrm{O}_{2} \\
\mathrm{O}_{3}^{-}+\mathrm{O}_{2}^{-}+\mathrm{O}_{2}^{-}+\mathrm{O}_{2} \\
\mathrm{O}_{3}^{-}+\mathrm{CO}_{2} \rightarrow \mathrm{CO}_{3}^{-}+\mathrm{O}_{2} \\
\mathrm{CO}_{3}^{-}+\mathrm{O}^{-} \rightarrow \mathrm{O}_{2}^{-}+\mathrm{CO}_{2} \\
\mathrm{CO}_{3}^{-}+\mathrm{NO} \rightarrow \mathrm{NO}_{2}^{-}+\mathrm{CO}_{2}\end{array}$ & $\begin{array}{l}2.0(-29) \\
1.4(-10) \\
4.0(-10) \\
8.0(-11) \\
9.0(-12)\end{array}$ & $\begin{array}{l}0 \\
0 \\
0 \\
0 \\
0\end{array}$ & $\begin{array}{l}0 \\
0 \\
0 \\
0 \\
0\end{array}$ \\
\hline $\begin{array}{l}\mathrm{CO}_{3}^{-}+\mathrm{NO}_{2} \rightarrow \mathrm{NO}_{3}^{-}+\mathrm{CO}_{2} \\
\mathrm{NO}_{2}^{-}+\mathrm{O}_{3} \rightarrow \mathrm{NO}_{3}^{-}+\mathrm{O}_{2} \\
\mathrm{O}_{4}^{-}+\mathrm{NO}^{-} \rightarrow \mathrm{NO}_{3}^{-}+\mathrm{O}_{2} \\
\mathrm{O}_{4}^{-}+\mathrm{CO}_{2} \rightarrow \mathrm{CO}_{4}^{-}+\mathrm{O}_{2} \\
\mathrm{CO}_{4}^{-}+\mathrm{NO} \rightarrow \mathrm{NO}_{3}^{-}+\mathrm{CO}_{2}\end{array}$ & $\begin{array}{l}8.0(-11) \\
1.8(-11) \\
2.5(-10) \\
4.3(-10) \\
4.8(-11)\end{array}$ & $\begin{array}{l}0 \\
0 \\
0 \\
0 \\
0\end{array}$ & $\begin{array}{l}0 \\
0 \\
0 \\
0 \\
0\end{array}$ \\
\hline $\begin{array}{l}\mathrm{CO}_{4}^{-}+\mathrm{O} \rightarrow \mathrm{CO}_{3}^{-}+\mathrm{O}_{2} \\
\mathrm{NO}_{3}^{-}+\mathrm{H}_{2} \mathrm{O}+\mathrm{O}_{2} \rightarrow \mathrm{NO}_{3}^{-} \cdot \mathrm{H}_{2} \mathrm{O}+\mathrm{O}_{2} \\
\mathrm{~N}_{+}^{+}+\mathrm{e} \rightarrow \text { products } \\
\mathrm{O}_{2}^{+}+\mathrm{e} \rightarrow \text { products } \\
\mathrm{NO}^{+}+\mathrm{e} \rightarrow \text { products }\end{array}$ & $\begin{array}{l}1.5(-10) \\
7.5(-29) \\
2.9(-7) \\
2.0(-7) \\
4.0(-7)\end{array}$ & $\begin{array}{l}0 \\
0 \\
0 \\
0 \\
0\end{array}$ & $\begin{array}{r}0 \\
0 \\
0 \\
-1 \\
-1\end{array}$ \\
\hline $\mathrm{XY}^{+}+\mathrm{e} \rightarrow$ products $^{c}$ & $1.0(-5)$ & 0 & 0 \\
\hline $\mathrm{X}^{+}+\mathrm{Y}^{-} \rightarrow$ products $^{d}$ & $1.0(-7)$ & 0 & 0 \\
\hline $\mathrm{W}^{-}+\mathrm{h} v \rightarrow$ products $+\mathrm{e}$ & 0.2 & 0 & 0 \\
\hline
\end{tabular}

A fast stiff differential equation solver, due to Gear (Ref. 38) was used to obtain the solutions of equations (30). The production and loss mechanisms of each species were determined automatically by the computer code by scanning the library of chemical reactions used in the model. Detalls of this computational scheme are described by Prasad and Huntress (Ref. 39) in the context of their model of interstellar chemistry, in which 137 species and more than 1,400 chemical reactions are involved.

Table 5 presents the values of the electron number density $n_{e}$, and the ratio of the concentration of negative lons to the concentration of electrons, $\lambda$, at various altitudes, with ambient abundances of water vapor and nitric oxide computed with the photochemical models. The data in Table 5 simulate globally averaged daytime equilibrium conditions. Our quiescent values of $n_{e}$ and $\lambda$ are consistent with observations and with the results from other models as described in the previously referenced texts and 
monographs. This demonstrates the adequacy of the model for the present assessment where only possible changes in the fonosphere due to alterations in the neutral atmosphere caused by HLLV operations are sought.

\section{THE ACCUMULATION AND DISPERSION OF ROCKET EXHAUST CONTAMINANTS}

The models described above have been used to simulate the accumulation and dispersion of the substances deposited during HLLV launch (water vapor, nitric oxide, carbon dioxide, carbon monoxtde, sulfur dioxide) and created during reentry (nitric oxide). In order to simulate the long-term effects, the 1-D and 2-D photochemical models were run for 10 years of continuous HLLV operations at the rate of 4000 launches per year with the injectants averaged over different horizontal extents (Northern Hemisphere, the globe, etc.). The 1-D model simulations appeared to have reached a steady state. The 2-D model simulations had closely approached a steady state in the mesosphere, but had not quite attained steady state in the stratosphere. The 1-D model directly simulated water vapor deposition at all altitudes up to $120 \mathrm{~km}$. Water vapor deposition at higher altitudes was simulated by inserting it into the model at $120 \mathrm{~km}$ altitude from where it could be transported downward or converted photochemically to $\mathrm{H}_{2}$ and flow upward as well as downward. The $\mathrm{H}_{2}$ could escape as discussed below. In the 2-D mode1, which did not contain $\mathrm{H}_{2}$, all water deposited above $90 \mathrm{~km}$ altitude was assumed to be injected at $90 \mathrm{~km}$; the upper boundary condition was constructed such that water vapor could move across the boundary seeking equilibrium of high-altitude water vapor (1.e., above $90 \mathrm{~km}$ ) with the water vapor below. The short-term effects are treated with the plume (d1spersion) model discussed in Sec. 2. In the present section we discuss the widespread accumulation of injectants under quasi-steady-state conditions and the dispersion of the water vapor contralls and reentry nitric oxide plumes for single events.

\subsection{Water Vapor}

The predicted increases in the water vapor abundance obtained with the $1-D$ and $2-D$ photochemical models for 10 years of HLLV operations are shown in Fig. 11. It is apparent from the results of the 2-D model that no significant "corridor effect" (enhanced accumulation in the vicinity of the launch latitude) is likely at altitudes below $70 \mathrm{~km}$. At an altitude of $85 \mathrm{~km}$ (the highest altitude at which the 2-D model yields reliable results) the computed corrodor enhancement is only $-15 \%$, which suggests that corridor effects are probably negligible at middle atmospherfc levels. Thus the changes in air composition caused by HLLV water vapor deposition can be adequately simulated with 1-D photochemical models. The globally averaged increase in $\mathrm{H}_{2} \mathrm{O}$ obtained with the $1-\mathrm{D}$ model is shown by the broken curve in Fig. 11. In the stratosphere (1.e., at altitudes below $50 \mathrm{~km}$ ) the two models predict nearly the same increase in water vapor. However, between 50 and $75 \mathrm{~km}$ (lower mesosphere), the increase obtained with the 2-D model is about double that obtained with the 1-D model. The difference is a consequence of the difference in vertical transport rates and the fact that the 2-D model does not simulate conversion of water vapor to $\mathrm{H}_{2}$; the vertical "eddy diffusion" coefficient in
Table 5. Simulated Unperturbed Daytime Globally Averaged Ionosphere

\begin{tabular}{ccccccc}
\hline $\begin{array}{c}\text { Altitude, } \\
\mathrm{km}\end{array}$ & $\begin{array}{c}{\left[\mathrm{H}_{2} \mathrm{O}\right],} \\
\mathrm{cm}^{-3}\end{array}$ & $\begin{array}{c}{[\mathrm{NO}],} \\
\mathrm{cm}^{-3}\end{array}$ & $\begin{array}{c}{[\mathrm{e}],} \\
\mathrm{cm}^{-3}\end{array}$ & $\begin{array}{c}{\left[\mathrm{X}^{-}\right],} \\
\mathrm{cm}^{-3}\end{array}$ & $\lambda^{b}$ \\
\hline 100 & $1.3(7)^{c}$ & $1.0(8)$ & $4.5(4)$ & $1.6(0)$ & $3.6(-5)$ \\
90 & $1.3(8)$ & $4.8(7)$ & $7.5(3)$ & $4.7(0)$ & $6.3(-4)$ \\
85 & $4.1(8)$ & $1.5(7)$ & $4.1(3)$ & $3.6(0)$ & $8.6(-4)$ \\
80 & $1.3(9)$ & $1.0(7)$ & $8.0(2)$ & $1.0(1)$ & $1.3(-2)$ \\
75 & $3.0(9)$ & $1.0(7)$ & $6.1(2)$ & $7.1(1)$ & $1.2(-1)$ \\
70 & $7.3(9)$ & $1.0(7)$ & $1.7(2)$ & $9.8(1)$ & $5.8(-1)$ \\
65 & $1.5(10)$ & $9.6(6)$ & $2.9(1)$ & $1.2(2)$ & $4.2(0)$ \\
60 & $3.0(10)$ & $6.5(7)$ & $7.6(0)$ & $2.0(2)$ & $2.6(1)$
\end{tabular}

$a_{\left[\mathrm{x}^{-}\right]} \equiv$ concentration of all negative ions.

$b_{\lambda} \equiv\left[\mathrm{X}^{-}\right] /[\mathbf{e}]$.

$c_{1.3(7)} \equiv 1.3 \times 10^{7}$. 
the 2-D model is somewhat smaller than that in the 1-D model. On the other hand, the actual value is uncertain and our results give an indication of the effects of this parameter on the $\mathrm{H}_{2} \mathrm{O}$ prediction.

Many meteorologists believe that the influx of water vapor to the stratosphere 1s controlled by the lowtemperature "cold trap" of the tropical tropopause (Refs, 14, 40, 41). The mechanisms that remove water vapor from the stratosphere are still unknown, but are probably dominated by subsidence at mid-latitudes and high latitudes. We have made such an assumption fn our model calculations. Another loss mechanism for water vapor is photochemical conversion to relatively inert molecular hydrogen in the mesosphere, mainly through the reaction sequence.

$$
\begin{array}{r}
\mathrm{H}_{2} \mathrm{O}+\mathrm{hV} \rightarrow \mathrm{OH}+\mathrm{H} \\
\mathrm{OH}+\mathrm{O}_{3} \rightarrow \mathrm{HO}_{2}+\mathrm{O}_{2} \\
\mathrm{H}+\mathrm{O}_{2}+\mathrm{M} \rightarrow \mathrm{HO}_{2}+\mathrm{M} \\
\mathrm{H}+\mathrm{HO}_{2} \rightarrow \mathrm{H}_{2}+\mathrm{O}_{2}
\end{array}
$$

Some of the $\mathrm{H}_{2}$ diffuses to the troposphere, and some is dissociated at high altitude, contributing to the hydrogen escape flux to space (for discussion of the escape mechanisms, see Ref. 42). According to recent measurements the hydrogen escape rate is $\sim 10^{8} \mathrm{H}$ atoms $\mathrm{cm}^{-2} \mathrm{sec}^{-1}$ (Ref. 43 ). An escape flux of this magnitude was imposed as an upper boundary condition on the hydrogen in our 1-D mode1.

Molecular hydrogen may also be converted back into water vapor by reactions such as

$$
\begin{aligned}
& \mathrm{O}\left({ }^{\mathrm{D} D}\right)+\mathrm{H}_{2} \rightarrow \mathrm{OH}+\mathrm{H} \\
& \mathrm{OH}+\mathrm{HO}_{2} \rightarrow \mathrm{H}_{2} \mathrm{O}+\mathrm{O}_{2}
\end{aligned}
$$

However, in the mesosphere, $\mathrm{H}_{2}$ is produced at the expense of $\mathrm{H}_{2} \mathrm{O}$, and diffuses into the stratosphere and eventually the troposphere.

The effect of the deposition of water vapor and hydrogen at high altitudes (up to $120 \mathrm{~km}$ ) is a substantial thermospheric buildup of molecular and atomic hydrogen. The $\mathrm{H}_{2}$ dominates below $\sim 120 \mathrm{~km}$ and the $\mathrm{H}$ above $120 \mathrm{~km}$ (e.g., see Refs. 43, 44). The computed increase in total hydrogen above $100 \mathrm{~km}$ (globally averaged) is one of about a factor of 2 ( 1 .e., a doubling of thermospheric $\mathrm{H}$ and $\mathrm{H}_{2}$ ). The implication of such a large increase in thermospheric hydrogen worldwide are beyond the scope of the present study, but must be boldly underscored. It has been suggested to the authors by B. M. MeCormac that the population of ring current protons in the magnetosphere could be substantially altered by charge exchange. We mention here that because combustion is not stolchiometric, hydrogen is deposited along with water vapor in a volumetric ratio of 0.3 . The $1-D$ model takes account of $H_{2}$ photochemistry, but the 2-D model does not.

Because the short-term local dispersion of water vapor rocket emissions is associated principally with the production of "contrafls" (small ice particles), we defer discussion of this problem to Sec. 8 .

\subsection{Nitric Oxide}

Nitric oxide deposited in the stratosphere during the launch phase of the HLLV leads to an increase in the global No abundance of less than $1 \%$ over ambient concentrations for 400 launches per year.

Mesospheric nitric oxide is not normally produced there. Rather, it is produced by photochemical processes in the stratosphere and the thermosphere and then transported upward or downward, respectively. The stratospheric source results from the reaction of $O\left({ }^{1} \mathrm{D}\right)$ with nitrous oxide, and thermospheric nitric oxtde is produced through the dissoctation of $\mathrm{N}_{2}$, mainly via ionic processes.

However, No created in the mesosphere and lower thermosphere during HLLV reentry can lead to substantial increases in its upper atmospheric abundance. The relative magnitude of the increase depends on the background No concentrations which are quite uncertain. Figure 12 shows the predicted absolute 1ncreases in No concentrations caused by 10 years of HLLV launches at the rate of 400 per year and reentry on the nominal trajectory. These represent less than $20 \%$ increases in No at all heights.

\footnotetext{
${ }^{2}$ Lockheed Palo Alto Research Laboratory, 1980.
} 
The "corridor" effect for NO is much more pronounced than was the case for water vapor. Nitric oxide has a rather short lifetime in the mesosphere, about 4 days at an altitude of $70 \mathrm{~km}$ and even shorter at higher altitudes. This is a consequence of rapid photolysis by solar ultraviolet radiation (refs. 7,45 ),

$$
\text { NO }+h v \rightarrow \mathrm{N}+\mathrm{O} \text {, }
$$

followed by the odd-nftrogen destruction reaction,

$$
\mathrm{N}+\mathrm{NO} \rightarrow \mathrm{N}_{2}+0 .
$$

of course, reaction (37) must compete with the No recycling reaction

$$
\mathrm{N}+\mathrm{O}_{2} \rightarrow \mathrm{NO}+\mathrm{O},
$$

which inhibits No loss; the rates of reactions (38) and (39) are comparable at the $70-\mathrm{km}$ altitude.

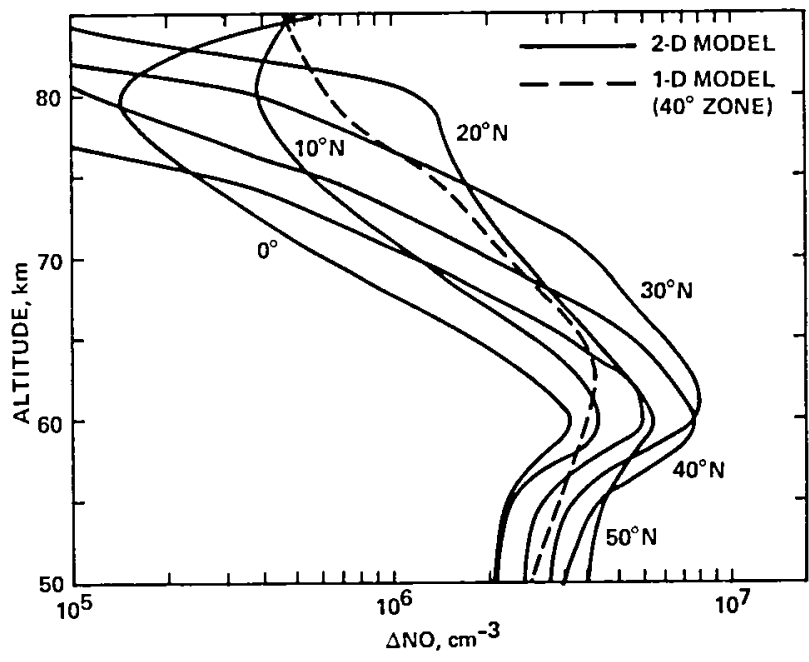

Fig. 12. Computed increase in mesospheric nitric oxide after $10 \mathrm{yr}$ of HLLV reentries.

The No lifetime can therefore be expressed as

$$
\mathrm{t}_{\mathrm{NO}} \approx \frac{\mathrm{k}_{38}[\mathrm{NO}]+\mathrm{k} 39\left[\mathrm{O}_{2}\right]}{2 \mathrm{~J}_{37} \mathrm{k}_{38}[\mathrm{NO}]} \text {. }
$$

In equation (40), $k$ denotes a rate coefficient and $J$ a photolysis rate; values of the reaction coefficients were taken from Ref. 6 and photolysis rates from Ref. 7. Since the concentration of $\mathrm{O}_{2}$ decreases rapidly with ascending altitude, the lifetime also decreases, reaching an asymptotic value of $\sim 2$ days at $90 \mathrm{~km}$. One can account for the relatively strong enhancement of No in the region of rocket reentry by noting that the NO is likely to be destroyed by the sequence of reactions (37) and (38) before it can be transported meriodionally over a significant distance. For the transport parameter values used in the 2-D model, the mean distance through which material is transported meridionally in 4 days is only $-400 \mathrm{~km}$.

The mesospheric source of nitric oxide includes photochemical reactions which dissociate $\mathrm{N}_{2}$, both EUV and X-rays (Ref. 46) as well as solar protons, meteorites (Ref. 33), etc. The I-D model includes such sources of NO as well as a flux from above $120 \mathrm{~km}$ of $\sim 10^{8}$ molecules $\mathrm{cm}^{2} \mathrm{sec}^{-1}$.

The NO predictions from the 1-D and 2-D models are in rough qualitative agreement, but differ in details. Because it is not possible to simulate the reentry trajectory in the 1-D model, substantial differences between the results from the two models are expected. Nitric oxide also cools the thermosphere in the

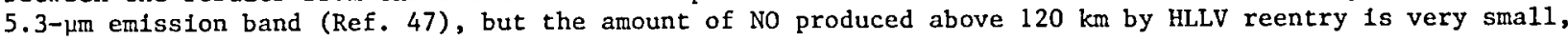
and this effect is expected to be negligible.

We have also simulated the dispersion of an No reentry trail with the aid of the plume model discussed in Sec. 2. Figure 13 illustrates the dispersal of No at points along the reentry flightpath where No 1s generated in large quantities (see Figs. 7,9). The horizontal eddy diffusivity employed for the calculations was $10^{8} \mathrm{~cm}^{2} \mathrm{sec}^{-1}$; actually, $\mathrm{K}$ is scale-dependent and hence is time-dependent (Ref. 48), 1ts effective value increasing with time. For periods of less than 1 day, $\mathrm{K} \approx 10^{8} \mathrm{~cm}^{2} \mathrm{sec}^{-1}$ is a reasonable value, but it increases rapidly thereafter, with the result that the trail undergoes rapid dispersal to concentrations approaching amblent values. The effect of such large No enhancements on 1onospheric structure will be discussed later.

\subsection{Carbon Dioxide and Carbon Monoxide}

The first stage of the HLLV burns methane fuel and carbon dioxide is a principal product of combustion. Since the methane molecule contains carbon and hydrogen atoms in the ratio of 1 to 4, assuming stoichiometric combustion one expects the volume rate of $\mathrm{CO}_{2}$ emission to be one half that of water vapor at altitudes below $56 \mathrm{~km}$. Actually, according to Ref. 1 , the combustion is not stoichlometric; the $\mathrm{CO}_{2}$ volume emission rate is about 0.4 that of water vapor and that for $\mathrm{co}$ is about 0.3 that for water 


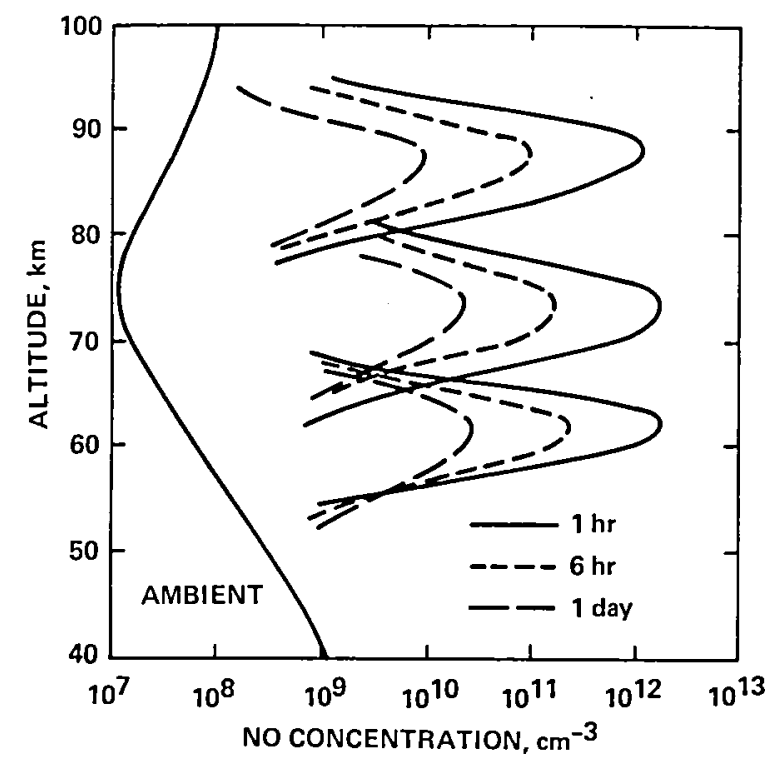

Fig. 13. Nitric oxide concentrations in a dispersing trail formed during the reentry of an HLLV. The plume model described in the text was used. The horizontal diffusion coefficient is $10^{8} \mathrm{~cm}^{2} \mathrm{sec}^{-1}$. Three sections of the plume along the reentry trajectory are shown. The ambient $1-D$ model nitric oxide profile is also given.

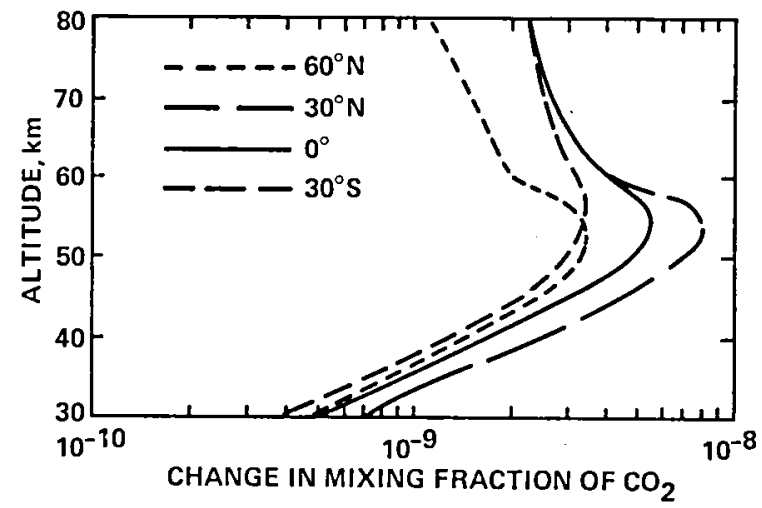

Fig. 14. Computed increase in the mixing ratio of carbon dioxide after 10 years of HLLV launches at a rate of 400 per year.
(Ref. 1). Although $\mathrm{CO}_{2}$ deposition ceases at an altitude of $56 \mathrm{~km}$, it is effectively mixed upward from that height because its only sink, diffusion to the troposphere, is a slow process. As a result, the absolute increase in the $\mathrm{CO}_{2}$ content should roughly approximate one half that for water vapor. Figure 14 shows the computed change in the mixing ratio of $\mathrm{CO}_{2}$ for several altitudes. The increase in the mixing ratio of $\mathrm{CO}_{2}$ at an altitude of $50 \mathrm{~km}$ therefore ranges from about $3 \times 10^{-3} \mathrm{ppmv}$ to about $7 \times 10^{-3}$ pprv, which should be compared with the mixing ratio in the ambient atmosphere of -300 ppmv. The fractional change is only about 1 to 2 parts in $10^{5}$, which seems to be much too small to cause a significant increase in the stratospheric-mesospheric cooling rate. If all of the cooling in this region were due to emission of infrared radiation by $\mathrm{CO}_{2}$, a very rough estimate of the resulting temperature change is $-10^{-3} \mathrm{~K}$ or less. The heating $\rightarrow$ cooling models described in Sec. 2.1 were used to confirm this estimate.

Carbon monoxide emitted by HLLV's cannot accumulate like $\mathrm{CO}_{2}$ because $\mathrm{Co}$ is rapidly oxidized to $\mathrm{CO}_{2}$. Afterburning in the rocket plume should convert most of the emitted $\mathrm{CO}$ into $\mathrm{CO}_{2} \cdot{ }^{3}$ otherwise, the $C 0$ will mix into the atmosphere and be oxidized principally by reacting with $\mathrm{OH}$,

$$
\mathrm{CO}+\mathrm{OH} \rightarrow \mathrm{CO}_{2}+\mathrm{H},
$$

with a rate coefficient $\sim 1 \times 10^{-13} \mathrm{~cm}^{3} \mathrm{sec}^{-1}$, corresponding to an upper atmospheric lifetime of ${ }^{\tau} \mathrm{CO} \leqslant 3$ months. Reactions of CO with $\mathrm{O}_{2}, \mathrm{O}_{3}$, $\mathrm{HO}_{2}$, etc., are extremely slow and can be ignored. Inasmuch as stratospheric $\mathrm{OH}$ concentrations are $\sim 1 \times 10^{7}$ molecules $\mathrm{cm}^{-3}$ (Ref. 13), the lifetime of injected co could be as short as 2 weeks, assuming $\mathrm{OH}$ levels are not greatly perturbed. co concentration increases would have to exceed $10^{10}$ molecules $\mathrm{cm}^{-3}$ to affect $\mathrm{OH}$ concentrations (background amounts of $\mathrm{CO}$ in the stratosphere vary from $\sim 2 \times 10^{10}$ molecules $\mathrm{cm}^{-3}$ near $20 \mathrm{~km}$ to $-1 \times 10^{9}$ molecules $\mathrm{cm}^{-3}$ near $40 \mathrm{~km}$ based on recent model calculations). Thus, if significant amounts of $\mathrm{CO}$ remained in the rocket plume, the $\mathrm{OH}$ abundance near the plume could be reduced by reaction (41). However, $\mathrm{OH}$ would also be influenced by the large quantity of water contained in the plume, which might compensate the co effect.

In the near-wake of the rocket, and in the launch corridor, Co buildups might be larger. High concentrations of emitted co could reduce oH levels, lengthening the residence time of $c 0$ in the exhaust plume. However, the plume would be rapidly diluted with ambient afr as it disperses, allowing the $0 H$ reaction cycle to begin depleting co quite efficiently, perhaps at a rate approaching (or, locally, exceeding) the global oxidation rate(s) estimated above. In addition, because actual co emissions are probably much lower than the upper-11mit values just considered, Co perturbations by SPS rockets will very likely be negliglble. Calculation with the 1-D model for the globally averaged case indicates that the co abundance would be increased by 1 ess than $10 \%$, which would have a negligible effect on the distributions of other constituents.

\footnotetext{
${ }^{3}$ Based on calculations supplied by K. L. Brubaker, Argonne National Laboratory.
} 


\subsection{Sulfur Dioxide}

It has been estimated ${ }^{4}$ that the first-stage fuel of the HLLV could contain $0.05 \%$ sulfur by mass. The yearly deposition of sulfur dioxide in the stratosphere is therefore estimated to be not more than $\sim 200$ tonnes $\mathrm{yr}^{-1}$, as compared with an estimated $\sim 2 \times 10^{5}$ tonnes $\mathrm{yr}^{-1}$ of $\mathrm{SO}_{2}$ produced in the stratosphere from $\operatorname{COS}$ of tropospheric origin (Ref. 49). Based on the work reported in Ref. 49, we estimate that the resulting fractional increase in the mass concentration of the stratospheric aerosol layer would be negligible and not affect Earth's albedo and mean surface temperature.

\section{PERTURBATIONS TO ODD-OXYGEN AND ODD-HYDROGEN}

The computed accumulations of excess water vapor and nitric oxide lead to predicted changes in the distribution of odd-oxygen and odd-hydrogen $\left(\mathrm{HO}_{\mathrm{x}}\right.$ ) species. The odd-hydrogen concentration is enhanced mainly through the reactions

$$
\begin{aligned}
0\left({ }^{1} \mathrm{D}\right)+\mathrm{H}_{2} \mathrm{O} & +2 \mathrm{OH} \\
\mathrm{H}_{2} \mathrm{O}+\mathrm{hV} & \rightarrow \mathrm{OH}+\mathrm{H}
\end{aligned}
$$

where water vapor photolysis occurs at high altitudes (above $70 \mathrm{~km}$ ).

The odd-hydrogen generated is distributed among several spectes including $\mathrm{H}, \mathrm{OH}, \mathrm{HO}_{2}$, and, at low altitudes, $\mathrm{H}_{2} \mathrm{O}_{2}$ and $\mathrm{HNO}_{3}$. Our computations show that the increases in $\mathrm{HO}_{\mathrm{x}}$ abundances are significant only in the mesosphere and thermosphere; in the stratosphere, fractional $\mathrm{OH}$ and $\mathrm{HO}_{2}$ increase only about $0.5 \%$ at $50 \mathrm{~km}$, and decrease with descending altitude. of course such stratospheric perturbations will influence the ozone column density somewhat, as is discussed below. Figure 15 shows computed absolute increases in $\mathrm{HO}_{\mathrm{x}}$ species concentrations. The calculations were carried out with the 1-D model for globally averaged conditions, which are approximate according to the 2-D results in Fig. 11 , indicating no strong corridor effect. Although the results for $\mathrm{OH}$ and $\mathrm{HO}_{2}$ from the $1-\mathrm{D}$ and $2-\mathrm{D}$ model agree quite well up to $60 \mathrm{~km}$, they diverge at higher altitudes. The predictions made with the 1-D model are probably more reliable because the chemical scheme used was more complete than the scheme used in the 2-D model, $\mathrm{H}_{2}$ was included in the $1-\mathrm{D}$ model, and the technique for simulating water vapor deposition above $90 \mathrm{~km}$ more realistic. At altitudes above 80 to $85 \mathrm{~km}$, the 2-D model predictions are not expected to be reliable in any case because of proximity to the upper boundary.

In the region near the mesopause, excess injected atomic hydrogen may influence the thermal balance. The chemiluminescent reaction with ozone,

$$
\mathrm{H}+\mathrm{O}_{3} \rightarrow \mathrm{OH}^{*}+\mathrm{O}_{2},
$$

would enhance hydroxyl (Meinel) vibrational band emission and cool the atmosphere. More importantly, hydrogen catalyzes odd-oxygen recombination through reaction (43) followed by

$$
\mathrm{OH}+\mathrm{O} \rightarrow \mathrm{H}+\mathrm{O}_{2} \text {. }
$$

The net reaction cycle releases as heat the chemical energy stored in atomic oxygen, providing an additional local heating source. We have not been able to quantitatively assess the importance of this heat source because of complications involving turbulent heat transport.

\footnotetext{
${ }^{4}$ By K. L. Brubaker, Argonne National Laboratory, 1980.
} 
In the mesosphere and upper stratosphere, odd-oxygen species, $0_{3}, O\left({ }^{3} \mathrm{P}\right)$, and $O\left({ }^{1} \mathrm{D}\right)$, are strongly influenced by the catalytic reaction sequences (43) and (44), in addition to the Chapman oxygen reactions.

other important catalytic cycles are

$$
\begin{array}{r}
\mathrm{H}+\mathrm{O}_{2}+\mathrm{M} \rightarrow \mathrm{HO}_{2}+\mathrm{M} \\
\mathrm{OH}+\mathrm{O} \rightarrow \mathrm{H}+\mathrm{O}_{2} \\
\mathrm{HO}_{2}+\mathrm{O} \rightarrow \mathrm{OH}+\mathrm{O}_{2} \\
\hline \text { net: } 0+0 \rightarrow \mathrm{O}_{2} ;
\end{array}
$$

and

$$
\begin{aligned}
& \mathrm{OH}+\mathrm{O}_{3} \rightarrow \mathrm{HO}_{2}+\mathrm{O}_{2} \\
& \mathrm{HO}_{2}+\mathrm{O} \rightarrow \mathrm{OH}+\mathrm{O}_{2} \\
& \hline \text { net: } \quad \mathrm{O}+\mathrm{O}_{3} \rightarrow 2 \mathrm{O}_{2} .
\end{aligned}
$$

The stratosphere is more complex than the mesosphere, but several key odd-oxygen reaction cycles have been 1dentifled:

$$
\begin{array}{r}
\mathrm{OH}+\mathrm{O}_{3} \rightarrow \mathrm{HO}_{2}+\mathrm{O}_{2} \\
\text { net: } \quad \mathrm{HO}_{2}+\mathrm{O}_{3}+\mathrm{OH}+2 \mathrm{O}_{2}
\end{array}
$$

and

$$
\begin{aligned}
& \mathrm{NO}+\mathrm{O}_{3} \rightarrow \mathrm{NO}_{2}+\mathrm{O}_{2} \\
& \mathrm{NO}_{2}+\mathrm{O} \rightarrow \mathrm{NO}+\mathrm{O}_{2} \\
& \text { net: } 0+\mathrm{O}_{3} \rightarrow 2 \mathrm{O}_{2} \text {. }
\end{aligned}
$$

Interestingly, nitric oxide deposited in the lower stratosphere may lead to ozone increases (Ref. 50) through the decomposition of peroxy compounds, e.g.,

$$
\begin{gathered}
\mathrm{NO}+\mathrm{HO}_{2} \rightarrow \mathrm{NO}_{2}+\mathrm{OH} \\
\mathrm{NO}+\mathrm{CH}_{3} \mathrm{O}_{2} \rightarrow \mathrm{NO}_{2}+\mathrm{CH}_{3} \mathrm{O} \\
\mathrm{NO}_{2}+\mathrm{h \nu} \rightarrow \mathrm{NO}+\mathrm{O}
\end{gathered}
$$

The critical reaction (49), also interferes with the odd-oxygen destructive cycles (32) and (45), and (32) and (46).

We have computed ozone column changes due to water vapor and nitric oxide injection by HLLV launch and reentry operations. The computed globally averaged ozone reductions due to water vapor deposition ( 400 launches $\mathrm{yr}^{-1}$ ) are about $0.01 \%$, with no apparent corridor effect. This is less than one tenth the ozone reduction computed for the Space shuttle. 5 Similar calculations have been made for nitric oxide deposition during atmospheric reentry. On the other hand, the predicted increase in ozone obtained with the $1-\mathrm{D}$ model is only $\sim 0.01 \%$. We attribute the difference between the two results mainly to differences in the simulation of transport; the 2-D model simulates horizontal transport, whereas the 1-D model does not. Of lesser importance are differences in mean sun angle (the 1-D model uses a mean solar zenith angle which is time invariant, while in the 2-D model, the solar zenith angle is latitude- and timeindependent) and to differences in lower boundary conditions. In the 2-D model, No is transported

${ }^{5}$ R. C. Whitten, unpublished computations. 
downward into the stratosphere and then stored below altitudes where it is photodissociated. Because of reaction (49) an ozone increase is predicted, about $0.02 \%$ globally averaged, using the $2-D$ model. The computed latitude dependence of the column increase is shown in Fig. 16a for two seasons. It should be noted that such increases are highly uncertain, and it may be just as likely that small ozone decreases would occur for No injection in the lower stratosphere (Ref. 51). Figure 16b shows predicted changes in ozone concentration as a function of altitude.

Figure 17 shows the computed changes in the ozone and atomic oxygen concentrations above $40 \mathrm{~km}$. There is reasonably good agreement between the globally averaged $1-D$ model results and the 2-D model results. The predicted changes in mesospheric odd oxygen species do not seem to be especially significant, except perhaps with respect to chemical heating near the mesopause; reductions in $O\left({ }^{3} \mathrm{P}\right)$ at the mesopause may lead to slightly lower mesospheric temperatures, but the magnitude of the cooling, although difficult to estimate, is probably small (recall that the o concentration is smaller because the $\mathrm{H}$ concentration is larger, so that the overall rate of the exothermic reaction cycle (43) and (44) is not altered as significantly).

\section{ROCKET CONTRAILS AND NOCTILUCENT CLOUDS}

Meinel et al. (Ref. 52) reported seeing mesospheric clouds to the west of Tucson, Arizona, on several evenings in 1963. The sightings were unusual in that natural NLC's are never observed at such low latitudes. Melnel et a1. correlated the events with rocket launches in southern California, and attributed the clouds to water vapor and particulates deposited near the mesopause by rocket engines. They likened the clouds to NLC.

Benech and Dessens (Ref. 53) also observed artificial noctilucent clouds (ANLC) on two evenings when test rockets were being accelerated through the upper mesosphere. On the second occasion, careful observations were made of the evolution of the cloud, which was visible against the darkening twilight sky for more than $30 \mathrm{~min}$. Initially, a bright exhaust trail appeared, but this quickly dissipated except for a short segment ( $10 \mathrm{~km}$ in length) near the mesopause height. The segment elongated over a 50-km horfzontal distance and eventually became distorted.

Benech and Dessens state that the rocket deposited $260 \mathrm{~g} \mathrm{H}_{2} \mathrm{O}, 520 \mathrm{~g} \mathrm{HCl}$, and $1,600 \mathrm{~g} \mathrm{Al}_{2} \mathrm{O}_{3}$ along the $10-\mathrm{km}$ segment of the trail that was persistent. It is interesting to note that $1 \mathrm{~kg}$ of $\mathrm{H}_{2} \mathrm{O}$ can be dispersed into $0.1 \mu \mathrm{m}$ 1ce spheres to produce a $30 \mathrm{~km}^{2}$ cloud with a vertical optical thickness of about $10^{-4}$; that 1 , a small noct1lucent cloud. The $1,600 \mathrm{~g}$ of $\mathrm{Al}_{2} \mathrm{O}_{3}$ alone would not be sufficient to form a vistble cloud, because the ejected particles are typically much smaller than $0.1 \mu \mathrm{m}$, and are optically transparent

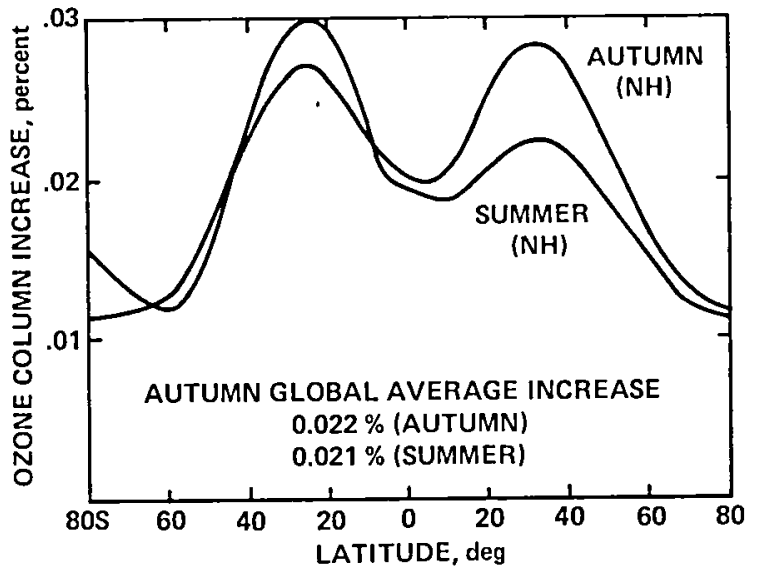

(a) Predicted relative Increase in the total column ozone density as a function of latitude and season corresponding to $\mathrm{NO}_{x}$ production due to reentry of $400 \mathrm{HLLV}^{\prime} \mathrm{s} \mathrm{yr}^{-1}$.

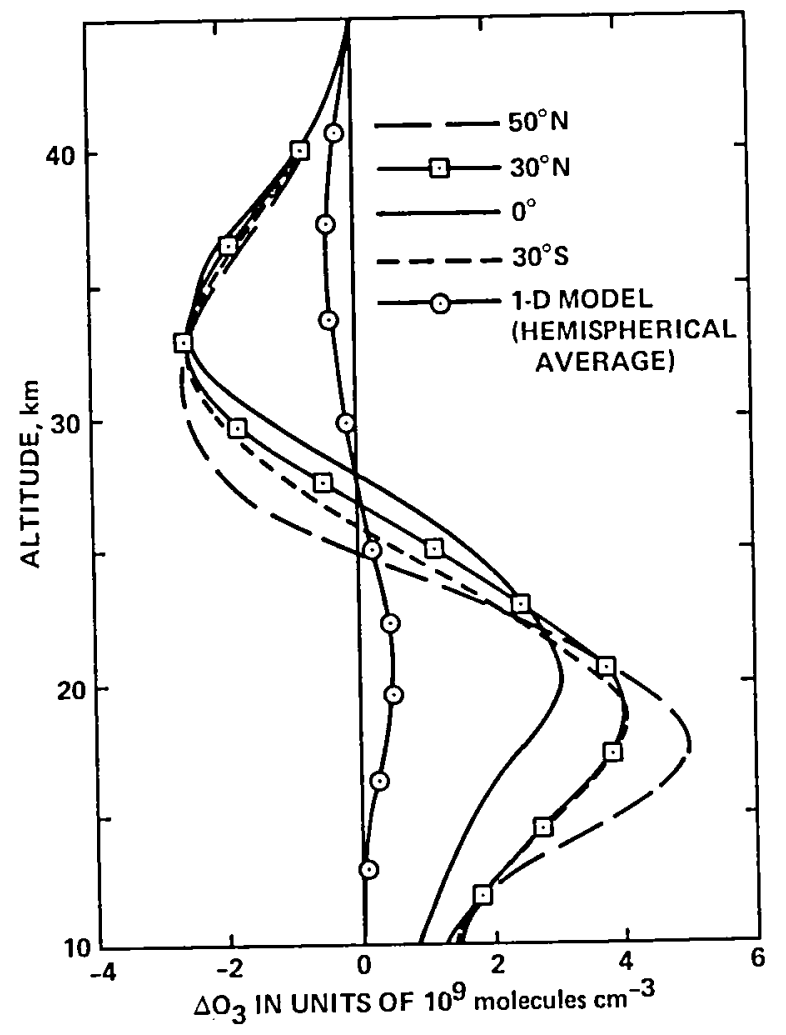

(b) Predicted changes in ozone concentration obtained with the 1-D and 2-D models.

Fig. 16. Ozone increases. 


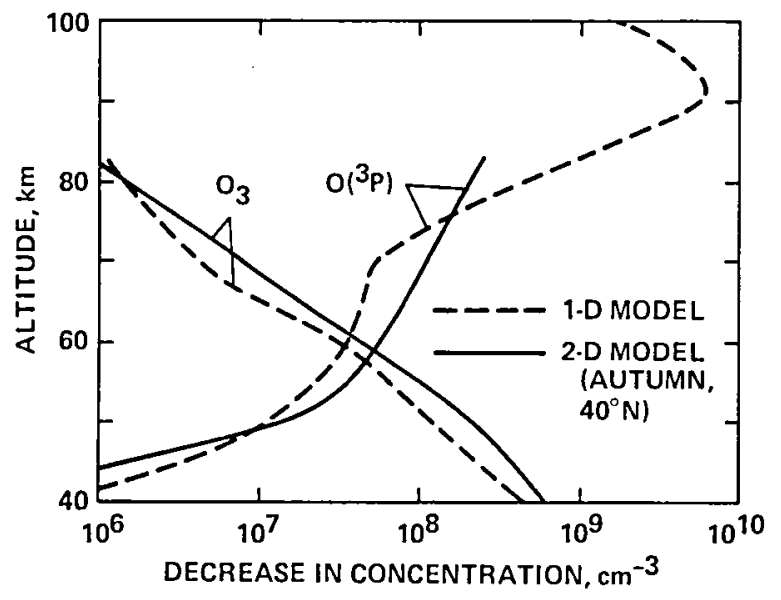

Fig. 17. Predicted changes in ozone and $0\left({ }^{3} \mathrm{P}\right)$ due to water vapor emission by HLLV's (400 launches $\mathrm{yr}^{-1}$ ).
(Ref. 54). On the other hand, $\mathrm{Al}_{2} \mathrm{O}_{3}$ particles are excellent ice sublimation nuclei. The combination of $\mathrm{H}_{2} \mathrm{O}$ and $\mathrm{HCl}$ could form a condensate of lower vapor pressure than pure water. The supersaturation required to nucleate $0.01 \mu \mathrm{m} \mathrm{Al}_{2} \mathrm{O}_{3}$ particles would also be lower than that required to nucleate the 0.001- $\mu \mathrm{m}$ meteoric dust normally found in the mesosphere. Benech and Dessens suggest in addition, that after sunset, the $\mathrm{Al}_{2} \mathrm{O}_{3}$ particles may be cooler than the ambient air due to efficient radiative cooling; this would give $\mathrm{Al}_{2} \mathrm{O}_{3}$ a further advantage as an ice nucleating agent.

Past observations of mesospheric clouds associated with rocket launches, therefore, indicate that tenuous short-11ved clouds are generated by solidfueled rockets, which emit copious quantities of sublimation nuclef. To our knowledge, mesospheric clouds have never been observed following any of the large Saturn $\mathrm{V}$ liquid fuel $\left(\mathrm{H}_{2}-\mathrm{O}_{2}\right)$ rocket launches from Cape Kennedy, Florida. The major exhaust constituent of those rockets is $\mathrm{H}_{2} \mathrm{O}$.

Admittedly, launches from Cape Kennedy could produce clouds far to the east of Florida where the prevailing winds could dissipate them before the first twilight. Yet, no reports of unusual nightluminous clouds, which might be expected with such large water injections, have been uncovered. Accordingly, there is little evidence linking large injections of (pure) water into the mesosphere with extensive persistent, optically-thick clouds.

Based on the projected SPS water vapor increases reported in Sec. 5, we expect less than a factor of 2 increase in water vapor between 80 and $90 \mathrm{~km}$ over the Northern Hemisphere due to SPS rocketry. Hence, the likely increase in the (average) noctilucent cloud opacity is $<10^{-4}$. We estimate a corresponding surface temperature change $\$ 0.01 \mathrm{~K}$ (Refs. 55,56 ), which is negligible.

The southern extent in latitude of noctilucent clouds, likewise, should not be greatly affected by SPS rockets. Normally, these clouds occur sporadically at latitudes as low as $45^{\circ}$. Theon et al. (Ref. 57) noted that NLC do not automatically occur whenever the mesosphere is extremely cold. They proposed that another factor, probably either an enhanced water vapor concentration or a suitable condensation nucleus is needed to form NLC. Thus, the change in water vapor induced by SPS rockets might increase slightly the frequency of NLC below $70^{\circ}$, without a measurable climatic effect. Above $70^{\circ}$ latitude, Donahue et al. (Ref. 58) detected (from the OGO-6 satellite) a persistent circumpolar cloud layer at $80 \mathrm{~km}$ in summer. Inasmuch as models of atmospheric circulation indicate substantial upward convection of air at the summer poles (Ref. 59), the likely source of water for the circumpolar clouds is the polar upper stratosphere. In Sec. 6 it was found that SPS rockets will not noticeably disturb the stratospheric water vapor reservoir. Thus, rocket $\mathrm{H}_{2} \mathrm{O}$ emissions should have an even smaller effect on circumpolar clouds than on lowlatitude NLCs.

Using the rocket plume "expansion" model outlined in Sec. 2.3 and the noctilucent cloud microphysics model described in Table 2, a rough simulation of an HLLV launch plume was made. We fgnore the complex aerodynamical effects in the early development of the rocket trafl, and assume that after a short relaxation time $(\sim 100 \mathrm{sec})$ the trail has reached temperature and pressure equilibrium with the ambient atmosphere and has a cross-sectional area of $\sim 1 \mathrm{~km}^{2}$. At this time, the exhaust water vapor is uniformly distributed across the plume, which is centered on the vertical axis of the $1-D$ NLC model. Of course, the initial concentration of water vapor in the plume is not allowed to exceed the local air density. Normally, contrails are seen just behind rockets, so that our initial spreading time of $\sim 100$ sec is somewhat artfficial; on the other hand, the initial adiabatic expansion of the plume is very rapid and cooling and nucleation can occur earlier.

In the plume model, a burst of homogeneous water nucleation occurs, and, because of the high supersaturation, these particles grow rapidly to sizes of $\sim 1 \mu \mathrm{m}$ (radius). As a result, the water vapor in the plume is consumed, the supersaturation over the (presumed) frozen particles falls to $\sim 0$, and further nucleation and growth ceases. It is important to note that the vapor pressure over ice is significantly lower than the vapor pressure over liquid water. Homogeneous nucleation produces supercooled water droplets, and, 
because the supercooled droplets may not freeze immediately, they may remain liquid throughout the growth phase. As the droplets froze, the contrail might take on the appearance of a cirrus cloud.

Subsequent to the termination of particle growth, the dominant contrail process is the expansion, which rapidly dilutes the particle concentration. Interestingly, the water vapor concentration is not diluted, because the water vapor remains in equilibrium with the particles, which evaporate and maintain a constant concentration of the vapor phase. Coagulation and sedimentation are important secondary processes. For example, the sedimentation rate of $1-\mu \mathrm{m}$ ice spheres at $80 \mathrm{kn}$ is about $60 \mathrm{~km} \mathrm{day}^{-1}$. We have neglected temperature feedback effects in the plume (infrared and ultraviolet radiation, photochemistry, and latent heat); proper treatment of these effects is beyond the scope of this assignment.

As the rocket trail continues to expand, the ratio of gaseous to condensed water increases steadily at each height (for a fixed ambient temperature). Eventually a point is reached where the particles begin to evaporate rapidly to maintain the vapor pressure of the water. At a given altitude this occurs when the plume has expanded to such a size that the total water vapor injected, if uniformly distributed over the plume area, would just produce ice saturation. Hence, after a short time, the contrail is confined to the coldest region of the mesosphere (assuming that the rate of horizontal expansion is roughly constant with height). The contrail also disappears abruptly when the water vapor in the coldest region becomes sufficiently diluted (allowing that the ambient water vapor concentration is moderately undersaturated). No persistent clouds are predicted because pure ice crystals cannot form and grow in the absence of sufficient water vapor saturation. Meteoric dust is present in the mesosphere (Ref. 60), but is probably too small $(<0.005 \mu \mathrm{m})$ to act as sublimation nuclei unless the supersaturation exceeds $\sim 10$ (Ref. 28).

Figure 18 summarizes the HLLV plume calculation. The initial optical depth along the axis of the contrail exceeds 100 . The opacity falls off rapidly as the plume expands. To be clearly visible in daylight, the opacity through the width of the contrail must exceed 0.1 . Note that, while the opacity along the axis of the trail decreases rapidly with time (approximately as $\mathrm{A}^{-1}$, where $\mathrm{A}$ is the cross-sectional area), the opacity across the trail decreases more slowly (roughly as $\mathrm{A}^{-1 / 2}$ ). Our calculations indicate that the trail could be visible for $12 \mathrm{hr}$ and cover an area of several hundred square kilometers. The actual horizontal extent of the contrail could be much larger because of the slant of the launch trajectory and the stretching and twisting of the trail by wind shears.

After several hours, the opacity of the trail begins to decrease at a faster rate because the ice particles at some altitudes are spontaneously evaporating.

A subvisible cloud could persist jor about 1 day before the water vapor saturation point was reached at all heights. This remnant contrail might produce a spectacular noctilucent cloud display at first dust or dawn after an HLLV launch.

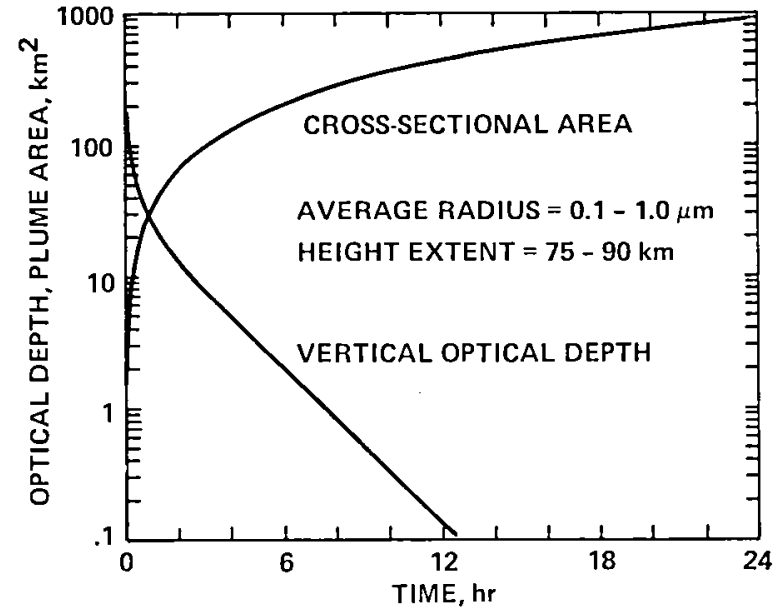

Fig. 18. Simulated HLLV launch plume characteristics. Shown are the (vertical) optical depth along the axis of the plume at $550 \mathrm{~nm}$, and the crosssectional area of the plume as a function of time after passage of the rocket. The average size of the ice particles in the plume and the height extent of the contrail are indicated in the figure.

In summary, we find that the effect of SPS rocket water vapor emissions on global cloud coverage is negligible from the point of view of climatic change. Preliminary simulations of rocket plumes indicate that contrails will form behind HLLVs and that they might persist for $\sim 1$ day. However, the contrails would cover only a small global area and have little climatic significance. Except for the possibility of impressive local noctilucent cloud displays in the launch corridor, we have uncovered no evidence for sustained, widespread clouds caused by liquid propellant rockets. We stress, however, that our conclusions are based on limited scientific data and approximate computer models and should be considered preliminary and tentative. 


\section{PERTURBATIONS OF THE LOWER IONOSPHERE}

\subsection{Long-Term Global Effects}

Increased water vapor in the fonospheric D-region due to HLLV launches is expected to increase the relative abundance of positive ions clustered to water molecules and to decrease the electron concentration, $\mathrm{n}_{\mathrm{e}}$, because the dissociative recombination of cluster ions is very fast. Our results, however, show no significant changes either in the electron density profile or in the total number densities of cluster ions. A globally averaged water vapor concentration profile appropriate for 400 HLLV launches per year (see Sec. 6.1) was used in calculating the perturbed ionosphere, and the number densities of No were fixed at ambient levels. HLLV-induced water vapor enhancements are appreciable (i.e., $\geq 20 \%)$ only in the upper D-region where water clustering to ions is inefficient. At lower altitudes $(\leqslant 80 \mathrm{~km})$ where clustering is rapid, the computed water vapor concentration increase was $\leqslant 15 \%$. This smal1 increase in water vapor could not cause a marked change either in $n_{e}$ or in the ionic composition, because there is already significant clustering at ambient water vapor levels. Although temperature changes alter the rates of cluster processes, the temperature changes caused by $\mathrm{H}_{2} \mathrm{O}$ (and NO) deposition are expected to have a negligible effect.

The adopted ambient nitric oxide concentrations, [NO], and the computed enhancements, $\Delta[$ NO] due to NO deposited by reentering space vehicles are shown in Table 6. Two cases are shown: (1) one using $\Delta[\mathrm{NO}]$ from the 1-D photochemical model and (2) one using similar data from the 2-D model. The limitations of the two models relative to No predictions discussed earlier suggest that these two $\Delta[$ [No] are good estimates of upper and lower bounds on $\Delta[N O]$. The computed values of $\Delta[$ NO] (the difference between columns 3 and 5 , and column 1) are as large as $30 \%$ so that the predicted changes in electron concentration are more noticeable than the effects of water vapor alone. This is evident from Table 6 which indicates small decreases in electron concentration at an altitude of $60 \mathrm{~km}$ and above $85 \mathrm{~km}$. These decreases are the result of increases in the dissociative recombination coefficients due to clustering of water vapor to ions. That decrease exceeds the increase in ionization rate due to enhanced No.

Table 6. Predicted Ionospheric Perturbations Due to Nitric Oxide Deposition

\begin{tabular}{|c|c|c|c|c|c|c|c|}
\hline \multirow{3}{*}{$\underset{\mathrm{km}}{\mathrm{Alt} .}$} & \multicolumn{2}{|c|}{ Unperturbed } & \multicolumn{4}{|c|}{ Perturbed } & \multirow{3}{*}{$\begin{array}{c}\text { Collision } \\
\text { frequency, } \\
a\end{array}$} \\
\hline & \multirow{2}{*}{$\begin{array}{l}{[\mathrm{NO}],} \\
\mathrm{cm}^{-3},\end{array}$} & \multirow{2}{*}{$\mathrm{cm}^{-3}$} & \multicolumn{2}{|c|}{ Case 1} & \multicolumn{2}{|c|}{ Case 2 } & \\
\hline & & & [NO ] & [e] & [No] & {$[\mathrm{e}]$} & \\
\hline 100 & $1.0(8)^{b}$ & $4.5(4)$ & $1.0(8)$ & $4.5(4)$ & 1.0 (8) & $4.5(4)$ & 3.2 (4) \\
\hline 90 & $4.8(7)$ & 7.5 (3) & $4.8(7)$ & 7.4 (4) & 4.8 (7) & 7.4 (3) & 1.9 (5) \\
\hline 85 & $1.5(7)$ & 4.1 (3) & $1.6(7)$ & $3.9(3)$ & $1.5(7)$ & 4.1 (3) & 4.5 (5) \\
\hline 80 & $1.0(7)$ & $8.0(2)$ & $1.1(7)$ & $8.3(2)$ & $1.0(7)$ & $8.2(2)$ & 1.1 (6) \\
\hline 75 & $1.0(7)$ & 6.1 (2) & $1.3(7)$ & 6.5 (2) & 1.2 (7) & 6.4 (2) & $2.4(6)$ \\
\hline 70 & $1.0(7)$ & 1.7 (2) & $1.4(7)$ & $1.9(2)$ & $1.4(7)$ & 2.0 (2) & $5.3(6)$ \\
\hline 65 & $9.6(6)$ & 2.9 (I) & 1.7 (7) & 3.4 (1) & $1.5(7)$ & 3.3 (1) & 1.1 (7) \\
\hline 60 & $6.5(7)$ & $7.6(0)$ & $7.3(7)$ & $7.2(0)$ & 7.4 (7) & $7.6(0)$ & $2.2(7)$ \\
\hline
\end{tabular}

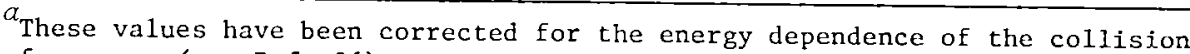
frequency (see Ref. 36).

$b_{1.0(8)} \equiv 1.0 \times 10^{8}$

The ionospheric D-region contributes significantly to the absorption of radio waves used in communications. The absorption coefficient is given by (approximately)

$$
\alpha=5.31 \times 10^{-8} \frac{\mathrm{n}_{\mathrm{e}}}{\mu v} \frac{v^{2}}{v^{2}+\left(\omega \pm \omega_{L}\right)^{2}} \mathrm{~m}^{-1} \text {, }
$$

where + and - signs refer to the ordinary and extraordinary modes, respectively, and where $\mu, \nu, \omega$, and $n_{e}$ are the real part of the refractive index, electron-neutral collision frequency, angular frequency of the radio wave, and electron density, respectively (Ref. 34); $\omega_{\mathrm{L}}$ is the product of the electron gyrofrequency and the cosine of the angle between Earth's magnetic field and the direction of the radio wave. When $\nu \gg \omega, \alpha \propto \mathrm{n}_{\mathrm{e}} / \nu$; on the other hand, if $\nu \ll \omega, \alpha \propto \mathrm{n}_{\mathrm{e}} \nu$. In either case, increased electron density in the $\mathrm{D}$-region could lead to increased absorption of radio waves. To obtain a simple estimate of this effect, let us consider HF waves (3-30 MHz) for which the D-region absorption would be 
given by

$$
\mathrm{L} \approx \frac{2.33 \times 10^{-6}}{\left(\mathrm{f}+\mathrm{f}_{\mathrm{L}}\right)^{2}} \quad \mathrm{n}_{\mathrm{e}} \nu \mathrm{dh} \mathrm{dB} \text { (mks units) }
$$

toward the upper portion of the range (Ref. 34) where the absorption is in $d B$ and the integral is.over the entire D-region (assumed here to extend from 65 to $85 \mathrm{~km}$ ). Using the values of $\mathrm{n}_{e}$ and $v$ from Table 6 , it is clearly seen that the D-region absorption of HF radio waves may be increased by about $10 \%$ during daytime. In comparison, much larger increases are encountered during large-scale geophysical disturbances (e.g., sudden ionospheric disturbances) which create serious communication problems. It is therefore doubtful whether the predicted $10 \%$ increase in D-region absorption would create a serious problem. Nevertheless, the question deserves more detailed examination. It should be pointed out that expression (53) does not apply at frequencies where $\omega \sim \nu$. Then a more complicated expression involving Dingle functions must be used (see Ref. 36).

Propagation of extremely low frequency (ELF) waves is controlled by the low frequency, or dc, conductivity of the air, particularly the conductivity scale height (Ref. 61). Our calculations show that the dc conductivity is hardly affected, the scale height even less so. Moreover, ELF communication links cover large horizontal distances, that is, latitudinal zones over which $\Delta[$ NO] and, consequently, changes in dc conductivity, may vary considerably in any case. The simple approach of Ref. 61 suggests a negligible effect of SPS on ELF propagation.

We looked for but could find no evidence that metal atoms would be deposited by ablation during HLLV reentry.

\subsection{Short-Term Local Effects}

Initially the nitric oxide,produced by a reentering SPS vehicle is extremely localized along the entry trajectory. With the passage of time, this dense column of No expands over wide regions. Table 7 presents computed No densities at various altitudes and at two times after the reentry, 6 hr and 1 day, obtained on the basis of the simplified No dispersion model discussed in Sec. 2.3. The corresponding daytime equilibrium electron concentrations are also shown in these tables. Clearly, a significant local ionospheric absorption could occur near the reentry point. There is therefore a need to reexamine this possibility, using more accurate mathematical models. It is also necessary to consider micrometeorological factors, for example, local winds, which might force the initial column to evolve differently on different days. On the other hand, it seems unlikely that large regions would be affected by radio wave disturbances.

Table 7. Nitric Oxide and Electron Concentrations Near Reentry

\begin{tabular}{cccccccc}
\hline \multirow{2}{*}{$\begin{array}{c}\text { Altitude } \\
\mathrm{km}\end{array}$} & \multicolumn{9}{c}{ NO } & \multicolumn{6}{c}{ Densities, $\mathrm{cm}^{-3}$} \\
\cline { 2 - 7 } & $6 \mathrm{hr}$ & \multicolumn{1}{c}{1 day } & $6 \mathrm{hr}$ & 1 day & $\begin{array}{c}\text { Unperturbed } \\
\mathrm{n}_{\mathrm{e}} \\
\text { from table }\end{array}$ \\
\hline 100 & $2.0(+9)$ & $6.0(+8)$ & $6.0(+4)$ & $4.8(+4)$ & $4.5(+4)$ \\
90 & $9.0(+10)$ & $9.0(+9)$ & $2.7(+5)$ & $8.6(+4)$ & $7.5(+3)$ \\
80 & $6.2(+10)$ & $1.2(+10)$ & $1.8(+5)$ & $7.3(+4)$ & $8.0(+2)$ \\
70 & $1.5(+11)$ & $2.5(+10)$ & $2.6(+4)$ & $8.0(+3)$ & $1.7(+2)$ \\
60 & $8.0(+10)$ & $1.5(+10)$ & $1.6(+1)$ & $8.5(+0)$ & $7.6(+0)$ \\
\hline
\end{tabular}

\subsection{Uncertainties}

Ionospheric D-region predictions are based on very uncertain physical systems. The uncertainties arise from a lack of information about the reactions occurring in the ionosphere, and of experimental values for certain parameters, such as rate constants and ionic mobilities. Observations of D-region electrons and ions of ten produce conflicting and inexplicable results. Thus, the accuracy of current ionospheric predictions is probably reasonable, but questionable. They are also limited by the accuracy of the predictions of neutral atmospheric changes. The predictions for short-term ionospheric effects are expected to be more uncertain than the long-term predictions, because the factors controlling the spatio-temporal evolution of $\Delta[$ NO] are more complex. The nature of the predicted ionospheric effects, however, suggest that this problem may need to be investigated more carefully. Our present results should therefore be regarded as preliminary estimates. 


\section{POSSIBLE CLIMATIC EFFECTS OF LARGE ROCKET OPERATIONS}

Some of the potential climatic effects of rocket clouds, for example, were mentioned in previous sections of this report. Here we discuss the more general mechanisms for climatic change.

Changes in the mixing ratios of radiatively active minor constituents caused by HLLVs could conceivably alter atmospheric heating rates and produce climatic changes (climate here is defined narrowly as the time-averaged meteorological state at Earth's surface). At least a 10-yr average would be required to obtain a representative climate that is not polluted by sampling error. Since compositional changes due to HLLV s are confined to levels above the midstratosphere, we must look for mechanisms that couple these higher levels with the troposphere. Such mechanisms can be radiative or dynamical. Radiative mechanisms involve perturbations of upper atmospheric composition or temperature that affect heating at the surface either through changes in the extinction of visible solar radiation or through changes in the transport of infrared radiation. Dynamical mechanisms involve high level circulation changes, including changes in reflection and absorption of planetary waves, that force changes in tropospheric winds, pressure, and temperature.

Radiative mechanisms for climatic change have been examined in a number of radiative-convective onedimensional models, including those of Ramanathan et a1. (Ref. 62), Schneider and Coakley (Ref. 63), and Manabe and Wetherald (Ref. 64). Such models examine the globally averaged radiative balance for various atmospheric compositions, with dynamics essentially excluded, except for the constraint that vertical temperature gradients cannot exceed the adiabatic lapse rate. An examination of the results of these models indicates that the most important changes in composition associated with HLLVs, namely decreases in ozone and increases in $\mathrm{H}_{2} \mathrm{O}$ and $\mathrm{NO}_{x}$, would not have a significant effect on climate, at least as measured by changes in surface temperature. For example, Ramanathan et al. (Ref. 62) computed a surface temperature increase of on $1 \mathrm{y} 0.06^{\circ} \mathrm{K}$ for a $10 \%$ increase in stratospheric water vapor. Since HLLVs are expected to produce at most a $0.5 \%$ increase in water vapor, their globally averaged effect through this mechanism can be ignored. Ozone decreases should be even less important, since they are concentrated strongly at levels well below the maximum in ozone heating at $50 \mathrm{~km}$. Even if ozone were to be decreased at all heights by the maximum value of $1 \%$, surface temperature decreases would amount to no more than $0.01^{\circ} \mathrm{K}$ (Ref. 62). This decrease would be made even smaller by the expected increase in $\mathrm{NO}_{\mathrm{x}}$, which acts to warm the troposphere by absorbing solar radiation reflected from the surface. Thus, on a globally averaged basis, radiative mechanisms would be ineffective in causing significant climate changes associated with HLLVs.

It is conceivable that the radiative effects could be enhanced by the formation of "corridors" of $\mathrm{H}_{2} \mathrm{O}$ and $\mathrm{NO}_{\mathrm{x}}$ enhancement (or ozone reduction). For example, if all the water vapor from the HLLVs were concentrated in a $5^{\circ}$ wide latitudinal band, water vapor increases of $10 \%$ within that band would be possible. However, this is not likely to result in a local $0.06^{\circ} \mathrm{K}$ increase in surface temperature, for horizontal heat transport w1ll smear out any synoptic scale heating on a much more rapid time scale than the several months it takes to build up significant water vapor increases. In any case, it was shown in Sec. 6 that the establishment of a water vapor "corridor" enhancement is highly unlikely.

It should be noted that cloud cover is an extremely important parameter in the assessment of climate and a critically uncertain one as well. However, it appears that changes in cloud cover associated with HLLVs will be insignificant. In the mesosphere, noctilucent cloud incidence is not likely to increase great ly, as shown in Sec. 8 of this report. As for the troposphere, changes in water vapor will be less than $0.1 \%$, hardly important for climatic change. Moreover, very little sulfur or particulate materials are expected from HLLVs, so that condensation or nucleation processes are not likely to be affected significantly.

Dynamical interactions between the troposphere and upper atmosphere have traditionally been thought of as a "one-way street," that is, the troposphere performs work on the stratosphere, but does not respond in turn to stratospheric motions. This is because stratospheric motions contain much less energy than tropospheric motions, which is due to the much lower mass of the stratosphere. The mean meridional circulation of the stratosphere, for example, would not have much effect on the troposphere since meridional wind speeds are comparable in magnitude to tropospheric wind speeds and thus much less energetic because of lower air density in the stratosphere. However, eddy motions, such as large-scale planetary waves, generally amplify as they propagate upward, maintaining a nearly constant energy per unit volume. If one allows for these waves to be reflected in the stratosphere by some mechanism, with the amplitude and phase of the reflected waves being governed by stratospheric conditions, it is possible for the stratosphere to have a feedback effect on tropospheric planetary waves. In fact, as Charney and Drazin (Ref. 65) pointed out, the westerly jet of the winter upper stratosphere does act as just such a reflection mechanism. The implications of this for changes in climate are significant, for 
if changes in the zonal jet could be reduced by compositional changes at high altitudes, planetary wave reflection characteristics would also be affected, thus affecting the phase or amplitude of planetary waves in the troposphere (Ref. 66).

A number of investigations have explored this mechanism, including those of Avery (Ref, 67) and Geller and Alpert (Ref. 68). These studies focused on the linear planetary wave response of a number of zonally averaged atmospheres to topographic and diabatic forclng. Comparison of results for different cases could then show whether different types of changes in the stratospheric zonal wind had significant effects on tropospheric climate. The major result of the studies is that zonal wind changes of $20 \%$ or more must occur below about $35 \mathrm{~km}$ for planetary wave phase or amplitude changes at the surface to approach the interannual varlability (Ref. 68). Of course, this result does not take into account the highly nonlinear nature of stratospheric motions; still, it is a good indication of the magnitudes necessary to cause significant dynamically induced climate change.

The Implications of this result for SPS operations can be crudely assessed by making some estimates for the effects of HLLV water vapor emission. The radiative-convective model of Manabe and Wetherald (Ref. 64) suggests a $10^{\circ} \mathrm{K}$ decrease in stratospherfc temperatures associated with a quintupling of water vapor. Scaling this down to an expected $10 \%$ maximum $\mathrm{H}_{2} \mathrm{O}$ increase if HLLV water vapor remains at low latitudes, we obtain temperature decreases of $\sim 0.2^{\circ} \mathrm{K}$. Comparing this with the equator-pole temperature gradient of about $40^{\circ}$ (which is proportional to the zonal wind strength), it can be seen that the maximum expected change in the zonal wind is on1y $0.5 \%$, well below the threshold for significant effects on reflected planetary waves. As before, HLLV-Induced ozone changes would have even less effect, since they are confined to levels above $40 \mathrm{~km}$.

Based on these estimates, we conclude that no significant effects on Earth's climate should result from the profected launch schedule of HLLVs $\left(400 \mathrm{yr}^{-1}\right)$. That is, we expect no temperature changes, locally or globally averaged, in excess of $0.1^{\circ} \mathrm{K}$ and no dynamical variations exceeding $5 \%$ of the interannul variability in planetary wave activity.

\section{SUMMARY}

Based on detafled theoretical analysis, it is apparent that we have uncovered no serious environmental hazards associated with operating HLLVs in the middle atmosphere. On the contrary, we conclude that:

1. "Corridor" effects, that is, enhancements of important constituents in a narrow latitude zone centered on the launch point, are not likely to occur. The reason is that merfdional transport is sufficiently rapid to spread the effluents fairly uniformly over the globe before a steady state is reached.

2. With the possible exception of mesospheric nitric oxide, changes in neutral composttion of the atmosphere below $90 \mathrm{~km}$ are not likely to be significant. Specifically, ozone decreases would probably not exceed $0.1 \%$ globally.

3. Deposition of carbon dioxide in the stratosphere should not cause noticeable changes in the stratospheric thermal balance; thus, the coupling to photochemistry is insignificant.

4. The climatic effects of extended HLLV operations are probably negligible. The effects considered here include enhancements of stratospheric aerosol opacity due to $\mathrm{SO}_{2}$ deposition by launch motors and alteration of planetary wave propagation characteristics in the stratosphere.

5. Perturbation of HF, VLF, and ELF communication links by launch and reentry operations will be minimal compared to normal variabllity and natural disturbances of the ionosphere. The widespread ionospheric effects are small (VLF and ELF), and short-term effects are localized (HF).

On the other hand, there are some potentfally important SPS effects that require further research:

6. There may be a worldwide buildup of thermospheric hydrogen, perhaps a doubling of the hydrogen globally for continuous $\mathrm{H}_{2}$ and $\mathrm{H}_{2} \mathrm{O}$ deposition above $70 \mathrm{~km}$. The enhanced hydrogen $1 \mathrm{n}$ the magnetospheric ring current region may reduce the population of current-carrying protons through charge exchange.

7. Extensive rocket contralls may form during HLLV launch and these may persist for a day or more, although extensive triggering of noctilucent clouds is highly unlikely. 
8. The D-region electron number density and conductivity may be greatly enhanced locally during atmospheric reentry. However, the modified region must be large If VLF and ELF propagation were to be affected.

On that note we conclude this report, hoping that future work will resolve the questions raised in items (6) and (8). 


\section{REFERENCES}

1. Satellite Power System Concept Development and Evaluation Program, Reference System Report, U.S. Department of Energy/NASA Report DOE/ER-0023, Washington, D.C. (1978).

2. Turco, R. P., and Whitten, R. C., A Comparison of Several Computational Techniques for Solving Some Common Aeronomic Problems, J. Geophys. Res. 79 (22), 3179-3185 (1974).

3. Turco, R. P., and Whitten, R. C., The NASA-Ames Research Center One- and Two-Dimensiona1 Stratospheric Models. I. The One-Dimensional Mode1, NASA TP-1002 (1977).

4. Boruck1, W. J., Whitten, R. C., Watson, V. R., Woodward, H. T., Riege1, C. A., Capone, L. A., and Becker, T., Predictions of Latitude-Dependent Ozone Depletion Due to Supersonic Transport Operations, AIAA Journal 12 (14), 1738-1745 (1976).

5. Whitten, R. C., Borucki, W. J., Watson, V. R., Shimazaki, T., Woodward, H. T., Riegel, C. A., Capone, I. A. and Becker, T., The NASA-Ames Research Center One- and Two-Dimensional Stratospheric Models. II. The Two-Dimensional Mode1, NASA TP-1003 (1977).

6. Hudson, R. D., and Reed, E. I. (Eds.), The Stratosphere: Present and Future, NASA RP-1049 (1979).

7. Nicolet, M., Photodissociation of Nitric Oxide in the Mesosphere and Stratosphere: Simplified Numerical Relations for Atmospheric Model Calculations, Geophys. Res. Lett., 6 (11), 966-968 (1979).

8. Nicolet, M., and S. Cieslik, The Photodissociation of Nitric Oxide in the Mesosphere and Stratosphere, Planet. Space Sci., 28 (1), 105-115 (1980).

9. Cogley, A. C., and Borucki, W. J., Exponential Approximation for Dafly Average Solar Heating on Photolysis, J. Atmos. Sc1. 33 (7), 1347-1356 (1976).

10. Turco, R. P., and Whitten, R. C., A Note on the Diurnal Averaging of Aeronomical Mode1s, J. Atmos. Terr. Phys. 40 (1), 13-20 (1978).

11. Maher, I. J., and Tinsley, B. A., Atomic Hydrogen Escape Rate Due to Charge Exchange with Hot Plasmaspheric Ions, J. Geophys. Res., 82 (4), 689-695 (1977).

12. Anderson, J. G., Rocket Measurement of OH in the Mesosphere, J. Geophys. Res., 76, $7820-7824$ (1971).

13. Anderson, J. G., The Absolute Concentration of $\mathrm{OH}\left(\mathrm{X}^{2} \pi\right)$ in the Earth's Stratosphere, Geophys. Res. Lett. $\underline{3}(3), 165-168(1976)$.

14. Ellsaesser, H. W., Harries, J. E., Kley, D., and Penndorf, R., Stratospheric $\mathrm{H}_{2} \mathrm{O}$, Planet. Space Sc1. (In press, 1980).

15. Howlett, L. C., Baker, K. D., Megill, L. R., Shaw, A. W., Pendleton, W. R., U1w1ck, J. C., Measurement of a Structured Profile of Atomic Oxygen in the Mesosphere and Lower Thermosphere, J. Geophys. Res., 85 (A3), 1291-1296 (1980).

16. Krueger, A. J., and Minzner, R. A., A Mid-Latitude Ozone Model for the 1976 U.S. Standard Atmosphere, J. Geophys. Res., 81 (24), 4477-4481 (1976).

17. Baker, K. D., Nagy, A. F., Olsen, R. O., Oran, E. S., Randhawa, J., Strobe1, D. F., and Tohmatsu, T., Measurements of the Nitric Oxide Altitude Distribution in the Mid-Latitude Mesosphere, J. Geophys. Res. 82 (22) 3281-3286 (1977).

18. Oort, A. H., and Rasmussen, E. M., Atmospheric Circulation Statistics, NOAA Paper 5, 1971.

19. Nastrom, G. D., and Belmont, A. D., Periodic Varlations in Stratospheric-Mesospheric Temperature from $20-65 \mathrm{~km}$ at $80^{\circ} \mathrm{N}$ to $30^{\circ} \mathrm{S}$, J. Atmos. Sc1., $32(9), 1715-1722$ (1975).

20. Cunnold, D., Alyea, F., Phillips, N., and Prinn, R., A Three-Dimenstona1 Dynamica1-Chemica1 Mode1 of Atmospheric 0zone, J. Atmos. Sci. 32 (1), 170-194 (1975). 
21. Newe11, R. E., Transfer Through the Tropopause and Within the Stratosphere, Quart. J. Roy. Meteorol. Soc., $89(380), 167-204(1963)$.

22. Brasseur, G., Un Modèle Bidimensionel du Comportement de l'Ozone dans la Stratosphère, Planet. Space Sci. 26 (2), 139-159 (1978).

23. Lacis, A. A., and Hansen, J. E., A Parameterization for the Absorption of Solar Radiation in the Earth's Atmosphere, J. Atmos. Sci., 31 (1), 118-133 (1974).

24. U.S. Air Force, Handbook of Geophysics, rev. ed., Macmillan, New York (1960).

25. Dickinson, R. E., Method of Parameterization for Infrared Cooling Between Altitudes of 30 and 70 kilometers, J. Geophys. Res. 78 (21), 4451-4457 (1973).

26. Bauer, E., Ol1ver, R. C., and Wasylkiwskyj, W., On the Use of Zirconium 95 Data from Chinese Atmospheric Thermo-nuclear Explosions to Study Stratospher1c Transport in a One-Dimensional Parametertzation, J. Geophys. Res. 83 (C8), 4019-4028 (1978).

27. Tozer, W. F., and Beeson, D. E., Optical Model of Noctilucent Clouds Based on Polarimetric Measurements from Two Sounding Rocket Campaigns, J. Geophys. Res., 79 (36), 5607-5612 (1974).

28. Turco, R. P., Toon, 0. B., Whitten, R. C., and Keesee, R. G., Noctilucent Clouds: Simulation Studies of Their Genesis, Properties, and Global Influences, (J. Atmos. Sci., submitted 1980).

29. DOE/NASA, Satellite Power Systems: Concept Development and Evaluation Program, U.S. Dept. of Energy Office of Energy Research Report DOE/ER-0023, NASA TM-79762, Oct. 1978.

30. Rockwell Internationa1, Aerodynamic Design Substantiation Report, Rockwell International Space Diviston Report SD74-SH-0206-1L, 1978.

31. U.S. Standard Atmosphere, NASA/NOAA/U.S. Air Force, Washington, 1976.

32. Park, C., Equivalent-Cone Calculation of Nitric Oxtde Production Rate During Space Shuttle Reentry (Atmos. Environment, in press 1980).

33. Park, C., and Menees, G. P., Odd N1trogen Production by Meteorolds, J. Geophys., Res., 83 (C8), 4029-4035 (1978).

34. Mitra, A. P., Ionospheric Effects of Solar Flares, D. Reidel Publishing Co., Boston (1974).

35. Rishbeth, H., and Garriott, O. K., Introduction to Ionospheric Physics, Academic Press, New York and London (1969).

36. Whitten, R. C., and Poppoff, I. G., Fundamentals of Aeronomy, John Wiley and Sons, New York, London (1971).

37. Banks, P. M., and Kockarts, G., Aeronomy, Part B, Academic Press, New York and London (1973).

38. Gear, C. W., Numerical Initial Value Problems in Ordinary Differential Equations, Prentice-Ha11, Englewood Cliffs, N.J. (1971).

39. Prasad, S. S., and Huntress, W. T., A Model for Gas Phase Chemistry in Interstellar C1ouds I. The Basic Mode1, Library of Chemical Reactions and Chemistry Among CN and O Compounds, Astrophys. J. Supp1. (in press, 1980).

40. Dobson, G. M. B., Brewer, A. W., and Cwilong, B., Meteorology of the Lower Stratosphere, Proc. Roy. Soc. A 185, 144-175 (1946).

41. Brewer, A. W., Evidence foi a World Circulation Provided by the Measurements of Helium and Water Vapour Distribution in the Stratosphere, Quart. J. Roy. Meteorol. Soc. 75, 351-363 (1949).

42. Chamberlain, J. W., Theory of Planetary Atmospheres, Academic Press, New York, San Francisco, London (1978). 
43. Liu, S. C., and Donahue, T. M., The Aeronomy of Hydrogen in the Atmosphere of the Earth, J. Atmos. Sc1., 31 (4), 1118-1136 (1974).

44. Hunten, D. M. , and Strobe1, D. F., Production and Escape of Terrestrial Hydrogen, J. Atmos. Sc1., 31 (2), 305-317 (1974).

45. Frederick, J. E., and Hudson, R. D., Predissociation of Nitric Oxide in the Mesosphere and Stratosphere, J. Atmos. Sc1., 36 (4), 737-745 (1979).

46. Strobe1, D. F., Nitric Oxide in the D-region, J. Geophys. Res., 77 (7), 1337-1339 (1972).

47. Kockarts, G., Nitric Oxide Cooling in the Terrestria1 Thermosphere, Geophys. Res. Lett., $\underline{7}$ (2), $137-140$ (1980).

48. Bauer, E., Dispersion of Tracers in the Atmosphere and Ocean, J. Geophys. Res. $\underline{79}$ (6), 780-795 (1974).

49. Turco, R. P., Whitten, R. C., Toon, O. B., Pollack, J. B., and Hamill, P., ocs, Stratospheric Aerosols and C1imate, Nature 283 (5744), 283-286 (1980).

50. Turco, R. P., Whitten, R. C., Poppoff, I. G., and Capone, L. A., SST's, Nitrogen Fertilizer and Stratospheric Ozone, Nature $276(5690), 805-807$ (1978).

51. Turco, R. P., Whitten, R. C., Toon, 0. B., Inn, E. C. Y., and Hami11, P., Stratospheric Hydroxy1 Radical Concentration: New Limitations Suggested by Observations of Gaseous and Particulate Sulfur, J. Geophys. Res. (1n press, 1980).

52. Meinel, A. B., Middlehurst, B., and Whitaker, E., Low-Latitude Noctilucent Cloud of 15 June 1963 , Science $141(3586), 1176-1178$ (1963).

53. Benech, B., and Dessens, J., Mid-Latitude Artificial Noctilucent Clouds Initiated by High-Altitude Rockets. J. Geophys. Res., 79 (9), 1299-1301 (1974).

54. Potter, A. E., Proceedings of the Space Shuttle Environmental Assessment Workshop on Stratospheric Effects, Report TMX-58198, NASA (1977).

55. Humme1, J. R., Contribution to Solar Albedo from a Mesospheric Aerosol Layer, J. Geophys. Res. $\underline{82}$ (13), 1893-1900 (1977).

56. Pollack, J. E., Toon, O. B., Sagan, C., Summers, A., Baldwin, B., and Van Camp, W., Volcanic Explosions and Climatic Change: A Theoretical Assessment, J. Geophys. Res. 81 (6), 1071-1083 (1976).

57. Theon, J. S., Nordberg, W., and Smith, W. S., Temperature Measurements in Noctilucent Clouds, Science 157 (3787), 419-421 (1967).

58. Donahue, T. M., Guenther, B., and Blamont, J. E., Noctilucent Clouds in Daytime: Circumpolar Particulate Layers near the Sumer Mesopause, J. Atmos. Sci. 29, 1205-1209 (1972).

59. Hesstvedt, E., Note on the Nature of Noctilucent Clouds, J. Geophys. Res. 66 (6), 1985-1987 (1961).

60. Hunten, D. M., Turco, R. P., and Toon, O. B., Smoke and Dust Particles of Meteoric Or1gin in the Mesosphere and Stratosphere, J. Atmos. Sci. (in press, 1980).

61. Gretfinger, C., and Greifinger, P., Approximate Method for Determining ELF Eigenvalues in the Earth-Ionosphere Waveguide, Radio Sci. 13 (5), 831-837 (1978).

62. Ramanathan, V., Call1s, L. B., and Boughner, R. E., Sensitivity of Surface Temperature and Atmospheric Temperature to Perturbations in the Stratospheric Concentration of Ozone and Nitrogen Dioxide, J. Atmos. Sci., 33 (6), 1092-1112 (1976).

63. Schneider, S. H., and Coakley, J. A., Sensitivity of Global Climate to SST-Induced Changes in Stratospheric Composition of $\mathrm{O}_{3}$ and $\mathrm{NO}_{2}$, Trans. Am. Geophys. Union (EOS) 55 (12), 1124 (1974). 
64. Manabe, S., and Wetherald, R. T., Thermal Equilibrium of the Atmosphere with a Given Distribution of Relative Humidity, J. Atmos. Sci., 24 (3), 241-259 (1967).

65. Charney, J. G., and Drazin, P. G., Propagation of Planetary Scale Disturbances from the Lower into the Upper Atmosphere, J. Geophys. Res. 66 (1), 83-109 (1961).

66. Hines, c. 0., A Posstble Mechanism for the Production of Sun-Weather Correlation, J. Atmos. Sc1., $31(2), 589-591(1974)$.

67. Avery, S., A Modeling Study of the Tropospheric Planetary Wave Response to Changes in Upper Atmospheric Reflection and Transmission, paper presented at the Conference on the Meteorology of the Upper Atmosphere, American Meteorological Society, Cambridge, Mass., Oct. 1978.

68. Geller, M. A., and Alpert, J. C., Planetary Wave Coupling between the Troposphere and the Middle Atmosphere as a Possible Sun-Weather Mechanism, unpublished manuscript, Rosenstiel School of Marine and Atmospheric Sclences, University of Miamf, Miami, Fla. (1980).

מ U S. GOVERNMENT PRINTING OFFICE: $1980-341-060 / 272$ 


$$
\text { - }
$$



United States

Department of Energy

Washington, D.C. 20585

Official Business

Penalty for Private Use, $\$ \mathbf{3 0 0}$
THIRD - CLASS MAIL.

POSTAGE \& FEES PAID

USS. DEPT. OF ENERGY

PERMIT NO. G 20

THIRD CLASS MAIL
Richard Gomberg

NASA Langley Research Center

NASA Langton, VA 23565

SP

3 